\title{
Modulator-Gated, SUMOylation-Mediated, Activity-Dependent Regulation of Ionic Current Densities Contributes to Short-Term Activity Homeostasis
}

\author{
Anna R. Parker, ${ }^{1}$ Lori A. Forster, ${ }^{2}$ and $\odot$ Deborah J. Baro ${ }^{1,2}$ \\ ${ }^{1}$ Department of Biology, and ${ }^{2}$ Neuroscience Institute, Georgia State University, Atlanta, Georgia, 30303
}

\begin{abstract}
Neurons operate within defined activity limits, and feedback control mechanisms dynamically tune ionic currents to maintain this optimal range. This study describes a novel, rapid feedback mechanism that uses SUMOylation to continuously adjust ionic current densities according to changes in activity. Small ubiquitin-like modifier (SUMO) is a peptide that can be post-translationally conjugated to ion channels to influence their surface expression and biophysical properties. Neuronal activity can regulate the extent of protein SUMOylation. This study on the single, unambiguously identifiable lateral pyloric neuron (LP), a component of the pyloric network in the stomatogastric nervous system of male and female spiny lobsters (Panulirus interruptus), focused on dynamic SUMOylation in the context of activity homeostasis. There were four major findings: First, neuronal activity adjusted the balance between SUMO conjugation and deconjugation to continuously and bidirectionally fine-tune the densities of two opposing conductances: the hyperpolarization activated current $\left(\mathrm{I}_{\mathrm{h}}\right)$ and the transient potassium current $\left(\mathrm{I}_{\mathrm{A}}\right)$. Second, tonic $5 \mathrm{nM}$ dopamine (DA) gated activity-dependent SUMOylation to permit and prevent activity-dependent regulation of $\mathrm{I}_{\mathrm{h}}$ and $\mathrm{I}_{\mathrm{A}}$, respectively. Third, DA-gated, activity-dependent SUMOylation contributed to a feedback mechanism that restored the timing and duration of LP activity during prolonged modulation by $5 \mu \mathrm{M}$ DA, which initially altered these and other activity features. Fourth, DA modulatory and metamoduatory (gating) effects were tailored to simultaneously alter and stabilize neuronal output. Our findings suggest that modulatory tone may select a subset of rapid activitydependent mechanisms from a larger menu to achieve homeostasis under varying conditions.
\end{abstract}

Key words: dopamine; HCN; KV4; metamodulation; short-term activity homeostasis; stomatogastric

Significance Statement

Post-translational SUMOylation of ion channel subunits controls their interactions. When subunit SUMOylation is dysregulated, conductance densities mediated by the channels are distorted, leading to nervous system disorders, such as seizures and chronic pain. Regulation of ion channel SUMOylation is poorly understood. This study demonstrated that neuronal activity can regulate SUMOylation to reconfigure ionic current densities over minutes, and this regulation was gated by tonic nanomolar dopamine. Dynamic SUMOylation was necessary to maintain specific aspects of neuronal output while the neuron was being modulated by high $(5 \mu \mathrm{M})$ concentrations of dopamine, suggesting that the gating function may ensure neuronal homeostasis during extrinsic modulation of a circuit.

\section{Introduction}

Neuron and network activity are robust despite their constant modulation. Stability is provided by compensatory processes that

Received May 30, 2018; revised 0ct. 23, 2018; accepted Nov. 3, 2018.

Author contributions: A.R.P. wrote the first draft of the paper; A.R.P., L.A.F., and D.J.B. edited the paper; A.R.P., L.A.F., and D.J.B. designed research; A.R.P., L.A.F., and D.J.B. performed research; A.R.P., L.A.F., and D.J.B. analyzed data; A.R.P. and D.J.B. wrote the paper.

This work was supported by National Science Foundation Grant 1456971 to D.J.B. and Georgia State University Brains and Behavior Pre-Doctoral Fellowships to A.R.P. and L.A.F. We thank our labmate, Meghyn A. Welch, for support and useful comments and anonymous reviewers for beneficial comments on previous versions of the manuscript.

The authors declare no competing financial interests. operate over multiple time courses. Slow negative feedback mechanisms act at the level of transcription to coordinate ionic current densities and thereby effect activity homeostasis (Linsdell and Moody, 1994; Golowasch et al., 1999a,b; Swensen and Bean, 2005; Peng and Wu, 2007; Olypher and Prinz, 2010; Driscoll et al., 2013; Kirchheim et al., 2013; Pozzi et al., 2013; O'Leary et al., 2014; Temporal et al., 2014). These slow mechanisms can stabilize neuronal output over the long-term but cannot offset fast 
positive feedback (Zenke et al., 2017). Although there are several examples of activity-dependent, post-translational processes that rapidly reconfigure ionic currents (Misonou et al., 2004; Mohapatra et al., 2009; Dupuis et al., 2014; Romer et al., 2014, 2016; Heubl et al., 2017), their roles in activity homeostasis remain largely unexplored. The work presented here identified a rapid, post-translational mechanism that contributes to activity homeostasis.

The pyloric network in the crustacean stomatogastric nervous system (STNS) is a premiere model system for investigating activity homeostasis. Studies using this motor central pattern generator have notably contributed to our current understanding of how stabilizing mechanisms generate component variability by producing compensatory changes in synaptic strengths and ionic current densities in response to altered activity (LeMasson et al., 1993; Prinz et al., 2004; Schulz et al., 2006; Marder, 2011; Zhao and Golowasch, 2012; O'Leary et al., 2014). This study focuses on a component of the pyloric circuit, the single, unambiguously identifiable lateral pyloric neuron (LP). The pyloric central pattern generator produces a continuous rhythmic output with a cycle period of $\sim 0.5-2 \mathrm{~s}$ (Marder and Bucher, 2007). LP fires a single burst of action potentials once within each cycle. The fraction of the cycle period in which LP remains active is termed LP duty cycle (LP burst duration divided by cycle period). While cycle period varies within and across individuals, LP duty cycle is invariant (Bucher et al., 2005; Goaillard et al., 2009). These data suggest that a feedback mechanism(s) adjusts LP burst duration to compensate for changes in cycle period. This study sought to identify that mechanism.

If a feedback mechanism senses changes in LP duty cycle, and rapidly reconfigures current densities to restore duty cycle over minutes, then those conductances must be continuously regulated according to duty cycle. Bidirectional alterations in LP duty cycle produce corresponding changes in the hyperpolarizationactivated current $\left(\mathrm{I}_{\mathrm{h}}\right)$ with a time constant of $\sim 10 \mathrm{~min}$, but only in the presence of tonic $5 \mathrm{~nm}$ dopamine (DA), which by itself does not modify the current (Krenz et al., 2013, 2015). LP I $\mathrm{h}_{\mathrm{h}}$ activity dependence required PKA, the $\mathrm{Ca}^{2+}$-calmodulin-dependent phosphatase, calcineurin, and it likely relied on calciuminduced-calcium-release (Krenz et al., 2015). We speculate that small ubiquitin-like modifier (SUMO) may also be involved, as SUMOylation of hyperpolarization-activated, cyclic-nucleotidegated $(\mathrm{HCN})$ channels that mediate $\mathrm{I}_{\mathrm{h}}$ can regulate their surface expression (Parker et al., 2016).

SUMO is an $\sim 11 \mathrm{kDa}$ peptide that can be conjugated to lysine residues on target proteins. SUMOylation influences proteinprotein interactions (Flotho and Melchior, 2013), and thereby shapes ion channel biophysical properties and surface expression (Henley et al., 2014; Qi et al., 2014; Benson et al., 2017; Xiong et al., 2017). Target protein SUMOylation states are dynamically regulated by the opposing actions of conjugating and deconjugating enzymes. Target protein phosphorylation status gates SUMO conjugation (Dustrude et al., 2016). Neuronal activity and activation of G-protein coupled receptors can alter the location of the SUMOylation machinery (Jaafari et al., 2013; Loriol et al., 2013, 2014), and target protein SUMOylation states can be adjusted in an activity-dependent manner (Chamberlain et al., 2012; Sun et al., 2014). Potentially, activity-dependent feedback could rapidly reconfigure numerous current densities by eliciting coordinated changes in the SUMOylation profile of multiple ion channels.

SUMOylation of the HCN channels that mediate $\mathrm{I}_{\mathrm{h}}$ and the $\mathrm{Kv} 4$ channels that mediate $\mathrm{I}_{\mathrm{A}}$ can influence their surface expres-
Table 1. Lobster SUMO primers

\begin{tabular}{ll}
\hline Primer description & ${\text { Sequence } \text { 5' }^{\prime} \text { to 3' }}^{\prime}$ \\
\hline Degenerate forward 1 & CAYATHAAYYCIAARGCISYIGG \\
Degenerate forward 2 & GTIGTICARTTYAARATHAARMRICAYAC \\
Degenerate reverse 1 & GTRTCIKTYTCRTTDATNGGYTG \\
Degenerate reverse 2 & TTDATNGGYTICCRTCRAAICKRAA \\
Specific forward 1 & CTCAAAAAGCTCATCAATGCCTACTG \\
Specific forward 2 & ATCAAAACTTGTCCAGACTACAGTGAG \\
Specific reverse 1 & CTCACTGTAGTCTGGACAAGTTTTGAT \\
Specific reverse 2 & CAGTAGGCATTGATGAGCTTTTGAG \\
Tat-SUM0 forward & TTTTGAATTCGAGTCCGAGGAGCCAAGAA \\
Tat-SUM0 reverse & GGGGGATTCTCACCCACCAGTTTGCTGCTGAACAC \\
NC-Tat-SUM0 reverse & GGGGGAATTCTCATGCAGCAGTTTGCTGCTGGAACAC \\
\hline
\end{tabular}

sion and biophysical properties (Parker et al., 2016; Welch et al., 2018). We hypothesize that LP duty cycle regulates the SUMOylation status of $\mathrm{Kv} 4$ and $\mathrm{HCN}$ channels to adjust their current densities to maintain duty cycle. Moreover, tonic $5 \mathrm{~nm}$ DA gates activity-dependent ion channel SUMOylation. The experiments herein begin to test these hypotheses.

\section{Materials and Methods}

Animals. California spiny lobsters, Panulirus interruptus, were purchased from Marinus Scientific and Catalina Offshore Products. Lobsters were maintained at $16^{\circ} \mathrm{C}$ in aerated and filtered seawater. Animals were anesthetized on ice before dissection. Male and female lobsters were used in these studies.

Chemicals. TTX was purchased from Tocris Bioscience, Tween 20 was purchased from Thermo Fisher Scientific, and all other chemicals were purchased from Sigma-Aldrich. DA was made fresh every $30 \mathrm{~min}$ to minimize oxidation.

SUMO cloning. A complete P. interruptus SUMO cDNA was isolated using a combination of degenerate PCR and RACE (GenBank accession: MF770707). Total RNA was isolated from lobster nervous system tissue with Trizol and used as the template in a reverse transcription reaction with Superscript according to manufacturer's instruction. The resulting cDNA served as a template in a degenerate PCR and RACE reactions as previously described (Clark et al., 2004). Degenerate primers (Table 1) were designed based on an alignment of Drosophila melanogaster Smt3 (GenBank accession: NM058063), Mus musculus SUMO 2 (GenBank accession: NM133354), and Mus musculus SUMO 3 (GenBank accession: $\mathrm{BC} 115488)$. The predicted $\sim 180 \mathrm{bp}$ PCR product was gel isolated and cloned into a pDrive vector (QIAGEN) and sequenced. Lobster-specific RACE primers (Table 1) were designed. The $3^{\prime}$ end of the SUMO transcript was obtained using lobster-specific forward primers (Table 1; Specific forward 1 and forward 2) and a SMARTer RACE kit (Clontech), following the manufacturer's instructions. The 5' end of the SUMO transcript was obtained using lobster-specific reverse primers (Table 1; Specific reverse 1 and reverse 2) and a FirstChoice RLM RACE Kit (Ambion). All sequencing was performed by the Georgia State University DNA core facility, and sequences were analyzed and manipulated with the Lasergene 10 suite of DNASTAR software.

Construction of a human embryonic kidney (HEK) cell line stably expressing a lobster HCN-GFP fusion protein for antibody validation. HCN was cloned and sequenced from $P$. interruptus nervous system tissue using standard previously described techniques (Clark et al., 2004). RNA was isolated and reverse transcribed into cDNA. A combination of degenerate PCR and RACE was used to isolate a full-length sequence. This sequence was novel and represented the 11th $\mathrm{HCN}$ channel isoform identified (GenBank accession: MH368784). Specific primers containing HCN start and stop sequences were then used in a standard PCR to amplify a full-length cDNA. The $5^{\prime}$ and $3^{\prime}$ primers also contained BglII and EcoRI sites, respectively. The PCR product was digested with BglII and EcoRI, gel isolated and cloned into a BglII and EcoRI digested pAcGFP1-C3 expression vector (Clontech) using standard techniques. The plasmid was transfected into HEK cells using Lipofectamine (Invitrogen). A clonal cell line stably expressing the lobster GFP-HCN fusion 
protein was obtained using previously described techniques (Parker et al., 2016).

Tat-SUMO peptide synthesis. A PCR product representing the activated form of lobster SUMO (i.e., ending in diglycine) was obtained using lobster nervous system cDNA, lobster-specific primers (Table 1; Tat-SUMO forward and reverse) and Titanium Taq (Takara) as described by the manufacturer. Standard recombinant DNA techniques were used to clone the predicted $274 \mathrm{bp}$ gel isolated PCR product into the EcoRI site of the pcDNA3 Tat HA vector (a gift from Matija Peterlin; Addgene plasmid \#14654) (Cujec et al., 1997), thereby creating an $\mathrm{N}$-terminal Tat-HA-His tagged SUMO construct. To synthesize the TatSUMO peptide, the plasmid was transformed in BL21-CodonPlus (DE3)-RIPL Escherichia coli (Agilent Technologies). A single isolated colony was grown overnight in $200 \mathrm{ml}$ of broth containing ampicillin $(100 \mu \mathrm{g} / \mathrm{ml})$ at $37^{\circ} \mathrm{C}$ with agitation. The $200 \mathrm{ml}$ overnight culture was then added to $1 \mathrm{~L}$ of broth containing $500 \mu \mathrm{M}$ isopropyl $\beta$-D-1thiogalactopyranoside (IPTG) to induce expression of the peptide, and further incubated for $5 \mathrm{~h}$. Cells were pelleted at $8000 \mathrm{rpm}$ for $10 \mathrm{~min}$ at $4^{\circ} \mathrm{C}$, and the pellet was washed with ice-cold PBS (137 mM NaCl, $2.7 \mathrm{~mm}$ $\mathrm{KCl}, 10 \mathrm{~mm} \mathrm{Na}_{2} \mathrm{HPO}_{4}, 1.8 \mathrm{~mm} \mathrm{K \textrm {K } _ { 2 }} \mathrm{PO}_{4}, \mathrm{pH}$ 7.4). Pelleted cells were resuspended in $20 \mathrm{ml}$ of Buffer $\mathrm{Z}$ ( $8 \mathrm{M}$ urea, $100 \mathrm{~mm} \mathrm{NaCl}, 20 \mathrm{~mm}$ HEPES, $\mathrm{pH} 8$ ) and sonicated on ice using a $10 \mathrm{~s}$ "on" $30 \mathrm{~s}$ "off" protocol at $15 \%$ amplitude for a total of $10 \mathrm{~min}$. Sonicate was cleared by centrifuging at $12,000 \mathrm{rpm}$ for $10 \mathrm{~min}$ at $4^{\circ} \mathrm{C}$. Cleared sonicate was equilibrated with 10 mM imidazole and incubated with $10 \mathrm{ml}$ of Ni-NTA agarose resin (QIAGEN) at $4^{\circ} \mathrm{C}$ for $1 \mathrm{~h}$. Resin was washed with $100 \mathrm{ml}$ of Buffer $\mathrm{Z}$ equilibrated with $10 \mathrm{~mm}$ imidazole. Peptide was eluted with incrementally increasing concentrations of imidazole $(100 \mathrm{M}, 250 \mathrm{M}, 500 \mathrm{~mm}$, and $1 \mathrm{M} ; 10 \mathrm{ml}$ each) and the buffer was exchanged for PBS with $10 \%$ glycerol using PD-10 desalting columns (GE Healthcare). Peptide concentration was determined by BCA assay (Pierce). The same strategy was used to obtain a second recombinant Tat-SUMO peptide to serve as a negative control. This second version of the peptide did not end in diglycine and could not be conjugated to a target protein. The nonconjugatable TatSUMO (NC-Tat-SUMO) was created using a PCR reverse primer in which the terminal diglycine was mutated to dialanine (Table 1; NC-TatSUMO Rev).

Immunoprecipitation from lobster nervous system lysates and Western blots. Lobster nervous system lysates were prepared by homogenizing lobster nervous system tissue in NP-40 lysis buffer $(50 \mathrm{~mm}$ Tris $\mathrm{HCl}, \mathrm{pH}$ $7.4,150 \mathrm{~mm} \mathrm{NaCl}, 1 \% \mathrm{NP}-40,20 \mathrm{~mm} \mathrm{NEM}$, protease inhibitor mixture at $1: 100)$. Homogenate was incubated at $4^{\circ} \mathrm{C}$ with agitation and then centrifuged at 12,000 rpm for 20 min to pellet cell debris. Protein concentration was determined by BCA assay (Pierce). Immunoprecipitation was performed using Dynabead Protein G (Invitrogen). Briefly, $10 \mu \mathrm{g}$ of antibody was incubated with the beads in $0.1 \mathrm{M} \mathrm{Na}$ acetate $\mathrm{pH} 5.3$ for $1 \mathrm{~h}$ at room temperature with agitation. Beads were washed three times with $0.1 \mathrm{~m} \mathrm{Na}$ acetate, $\mathrm{pH} 5.3$, plus $0.01 \%$ Tween $20 ; 2 \mathrm{mg}$ of cell lysate was added to the beads, and the mixture was incubated for $90 \mathrm{~min}$ at room temperature with agitation. Finally, the beads were washed three times with PBS plus $0.01 \%$ Tween 20 and eluted in $20 \mu \mathrm{l}$ of $50 \mathrm{~mm}$ glycine, $\mathrm{pH}$ 2.8 , by heating to $70^{\circ} \mathrm{C}$ for $10 \mathrm{~min}$. Western blot experiments were as previously described (Parker et al., 2016). Primary antibody concentrations used for Western blots were as follows: anti-HCN, 1:5000; antiORF-J, 1:4000; anti-SUMO, 1:4000.

Antibodies. All secondary antibodies were obtained from Jackson ImmunoResearch Laboratories. An antibody against the lobster HCN channel (anti-HCN) was custom-made. PCR was used to obtain a fragment of DNA corresponding to amino acids $362-390$ in the P. interruptus HCN channel. The gel-isolated PCR product was cloned into a PGex vector (GE Healthcare), and the recombinant peptide was isolated from E. coli according to the manufacturer's instructions. The peptide served as an immunogen and was injected into a rabbit. Serum obtained from an immunized rabbit was affinity-purified on a column containing the antigenic peptide using previously described techniques (Baro et al., 2000). The specificity of the antibody was validated as described in Results.

Bethyl Laboratories was contracted to produce a custom-made affinity-purified goat polyclonal antibody against a peptide corresponding to a specific segment of the Kv4 (shal) protein termed ORF-J (5'-
CVGGPPLHPSAITTTNTNTAT-3') (Baro et al., 2001). The specificity of the antibody was validated as described in Results.

The primary antibody against mouse SUMO-1 was obtained from Santa Cruz Biotechnology (\#sc-9060). SUMO is highly conserved across species, and a commercially available, affinity-purified, rabbit polyclonal antibody against mouse SUMO1 (anti-SUMO1) was used at 1:4000. The specificity of the antibody was validated as described in Results.

The primary antibody against HIV Tat (anti-Tat) was obtained from Abcam (\#ab63957). The specificity of anti-Tat was validated by the company. Immunohistochemistry experiments on whole-mount stomatogastric ganglia (STG) were performed as previously described (Baro et al., 2000; Oginsky et al., 2010).

The primary antibody against GFP (anti-GFP) was obtained from Abcam (\#ab290). The specificity of anti-GFP was validated by the company. Immunoprecipitation experiments with HEK cell lysates were as previously described (Parker et al., 2016).

STNS dissection, LP identification, and quantification of activity features. The STNS was dissected and pinned into a Sylgard dish (Selverston et al., 1976). The STG was desheathed and isolated with a Vaseline well. The STG was constantly superfused with aerated Panulirus saline (479 $\mathrm{mm} \mathrm{NaCl}, 12.8 \mathrm{~mm} \mathrm{KCl}, 13.7 \mathrm{~mm} \mathrm{CaCl}_{2}, 39 \mathrm{~mm} \mathrm{Na}_{2} \mathrm{SO}_{4}, 10 \mathrm{~mm} \mathrm{MgSO}_{4}$, 2 mm glucose, 4.99 mm HEPES, 5 mm TES, pH 7.4). Extracellular recordings were obtained by placing stainless-steel pin electrodes, connected to a differential AC amplifier (A-M Systems), directly against the pyloric dilator nerve $(p d n)$ and lateral ventricular nerve $(l v n)$ and insulating them with Vaseline. Intracellular somatic recordings were obtained using a high-resistance electrode filled with $3 \mathrm{M} \mathrm{KCl}(20-30 \mathrm{M} \Omega)$ and an Axoclamp 900A amplifier (Molecular Devices). Neurons were identified by correlating action potentials from somatic intracellular recordings with extracellularly recorded action potentials on identified motor nerves, and by their characteristic shape and timing of oscillations. The LP neuron is recognizable on the $l v n$ by the pattern and amplitude of its spikes (see Results). Measurements from the $l v n$ were used for quantification of LP activity as described in Results. Twenty cycles were used for each time point. LP on-delay was measured as the time between the last PD spike and the first LP spike.

Somatic two-electrode voltage-clamp (TEVC). All experiments were performed at $19^{\circ} \mathrm{C}-22^{\circ} \mathrm{C}$ as measured with a temperature probe in the bath. Temperature changed by $<1^{\circ} \mathrm{C}$ during an experiment. For TEVC experiments, LP was impaled with two low resistance glass microelectrodes filled with $3 \mathrm{M} \mathrm{KCl}(7-10 \mathrm{M} \Omega)$ connected to an Axoclamp 900A amplifier. The STG was superfused with Panulirus saline containing TTX (100 nM) to block voltage-dependent $\mathrm{Na}^{+}$channels. No other ion channel blockers were included. TEVC was used to implement voltage protocols described in Results and to measure $\mathrm{LP}_{\mathrm{h}}$ and $\mathrm{I}_{\mathrm{A}}$.

LP $I_{h}$ was elicited using a series of $4 \mathrm{~s}$ voltage steps from the holding potential of $-50 \mathrm{mV}$ to $-120 \mathrm{mV}$ in $10 \mathrm{mV}$ increments with $6 \mathrm{~s}$ between each step (Fig. 1A). LP $\mathrm{I}_{\mathrm{h}}$ steady-state peak current was measured by subtracting the initial fast leak current from the slowly developing $I_{h}$ at the end of each voltage step. Current was converted to conductance using $\mathrm{E}_{\text {rev }}=-35 \mathrm{mV}$ (Kiehn and Harris-Warrick, 1992) and fitted to a firstorder Boltzmann equation (Fig. $1 B$ ) to obtain maximal conductance $\left(G_{\max }\right)$ and the voltage of half-activation $\left(\mathrm{V}_{1 / 2}\right)$. This current could be completely blocked by the specific HCN channel blocker, ZD7288 (Fig. $1 C$ ). In addition, preliminary experiments showed that blocking $\mathrm{K}^{+}$ inward rectifier currents (Kir) with $200 \mu \mathrm{M} \mathrm{Ba}^{2+}$ had no significant effect on $\mathrm{LP} \mathrm{I}_{\mathrm{h}} \mathrm{G}_{\max }$.

LP $I_{A}$ is usually measured as a difference current. A depolarizing test pulse is preceded by a hyperpolarizing prepulse to either $-90 \mathrm{mV}$, where $\mathrm{Kv} 4$ channels are fully deinactivated, or $-40 \mathrm{mV}$, where $\mathrm{Kv} 4$ channels are largely inactivated. When the two traces are digitally subtracted, noninactivating currents are removed from the difference current. In the past, $\mathrm{Cd}^{2+}$ was included in the saline to block $\mathrm{Ca}^{2+}$ currents and G/V plots were always well fitted by Boltzmann equations to obtain $\mathrm{I}_{\mathrm{A}} \mathrm{G}_{\max }$ (Baro et al., 1997; Zhang et al., 2010). $\mathrm{Ca}^{2+}$ channel blockers were omitted here to examine activity-dependent processes. As a result, a previously described small, transient Cav2-mediated $\mathrm{Ca}^{2+}$ current with a steady-state inactivation profile highly similar to $\mathrm{I}_{\mathrm{A}}$ was represented in the difference current (Ransdell et al., 2013), and G/V plots were not well fitted with a 
A
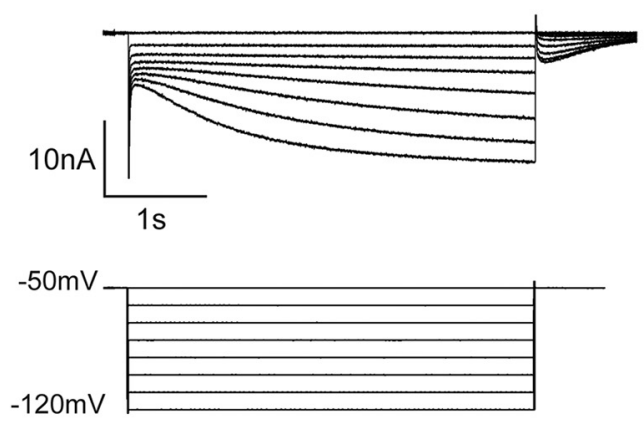

C

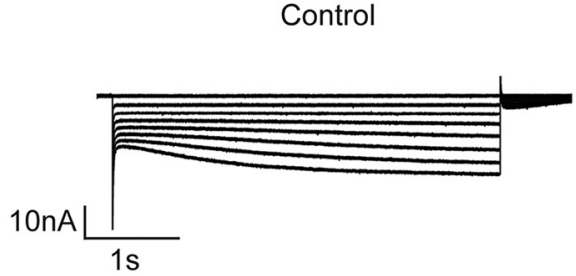

B

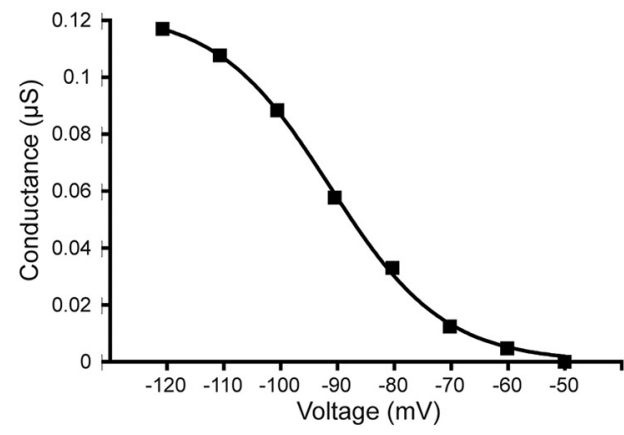

ZD7288

Figure 1. TEVC of LPI $I_{h} \cdot A$, Typical $L P I_{h}$ recording. Top, Current traces. Bottom, Voltage protocol. Calibration: $1 \mathrm{~s}, 10 \mathrm{nA} . \boldsymbol{B}, I_{h}$ Voltage dependence of activation. Plots of peak conductance versus voltage were fitted with a Boltzmann equation to obtain $\mathrm{I}_{\mathrm{h}} \mathrm{G}_{\max } \mathrm{C}_{\mathrm{h}} \mathrm{I}_{\mathrm{h}}$ is not contaminated with other inward currents. Representative traces measured before and after application of the selective inhibitor, ZD7288. Calibration: 1 s, $10 \mathrm{nA}$.

Boltzmann equation. Addition of $\mathrm{Cd}^{2+}$ to the saline restored the fit. Because $I_{A} G_{\max }$ could not be obtained by the usual method, LP $I_{A}$ was measured as the peak difference current at $40 \mathrm{mV}$ where the effect of the Cav2 current was minimal (Johnson et al., 2003; Ransdell et al., 2013). The length of the test pulse used was either 500 or $60 \mathrm{~ms}$. Preliminary experiments showed that the activity- and DA-dependent changes studied here represented alterations in peak $\mathrm{I}_{\mathrm{A}}$, as opposed to contaminating currents. Previous work showed that $4 \mathrm{~mm} 4$-AP could block $\mathrm{I}_{\mathrm{A}}$ in spiny lobster pyloric neurons (Tierney and Harris-Warrick, 1992). Here, 4 mM 4-AP largely blocked the peak difference current at $40 \mathrm{mV}$ (Fig. 2A). The residual current that remained in 4 -AP was not modulated by activity (Fig. 2B).

TEVC was used to deliver a series of voltage steps to mimic or alter LP duty cycle as described in Results. Protocols to exactly mimic, increase, or decrease duty cycle were applied sequentially. In these cases, the order of the protocols was deliberately switched from one experiment to the next. This did not affect the results. In previous studies on $\mathrm{I}_{\mathrm{h}}$ (Krenz et al., 2013, 2015), and in preliminary studies on $I_{A}$, protocols were not sequentially applied and each preparation received a single protocol. The results were the same for both types of applications.

Experimental design and statistical analysis. No statistical methods were used to compute sample size. All data were analyzed using Prism 7 (GraphPad Software). Each dataset was checked for normality and homogeneity of variance; and unless otherwise stated, data were analyzed using parametric statistical tests. In all cases, the significance threshold was set at $p<0.05$. Values that were $>2$ SDs from the mean were considered statistical outliers and were excluded from the dataset. ANOVA was followed by post hoc test as indicated. All values are presented as mean \pm SEM. Complete results of all statistical tests for each experiment are presented in the figure legends.

\section{Results}

DA reconfigures the activity dependence of $L P I_{A}$

LP undergoes constant $\sim 20 \mathrm{mV}$ oscillations in membrane potential that traverse the $\sim-60$ to $-40 \mathrm{mV}$ range with a plateau of variable duration at the most depolarized potential (Fig. $3 A$ ). This slow-wave activity is generated in the somatodendritic compartment. Spiking activity is generated at the spike initiation zone located at the beginning of the axon. Spikes emerge from a flat baseline and do not actively propagate into the somatodendritic compartment; rather, they passively spread and can be seen riding on the depolarized plateau in somatic intracellular recordings. Slow-wave activity can be described by duty cycle, defined here as plateau duration divided by cycle period. Thus, duty cycle represents the fraction of the cycle period for which LP is maximally depolarized, and presumably, $\mathrm{Ca}^{2+}$ influx into the somatodendritic compartment is greatest. We previously demonstrated that changes in duty cycle could bidirectionally regulate LP $I_{h}$, but only in the presence of tonic nM DA, which by itself had no effect on the current (Krenz et al., 2015). Here we tested whether or not duty cycle could also regulate $\mathrm{LP} \mathrm{I}_{\mathrm{A}}$.

The experiment is diagrammed in Figure $3 A$. The preparation was dissected, continuously superfused with saline, and the LP neuron was electrophysiologically identified. At $t=-10 \mathrm{~min}$, we measured peak and nadir voltages of the LP oscillation, plateau duration, and cycle period. The measured parameters were then used to construct three Clampex voltage protocols to manipulate the duty cycle of that particular neuron. Duty cycle was maintained using a $0 \% \Delta \mathrm{DC}$ protocol that generated a repeating voltage step with characteristics that exactly mimicked the measurements obtained at $t=-10 \mathrm{~min}$ (Fig. $3 A$ ). Duty cycle was increased by $50 \%$ using a $50 \% \Delta \mathrm{DC}$ protocol that increased the duration of the depolarized step by $50 \%$ and decreased the time between steps to maintain a constant cycle period. Duty cycle was decreased using the $-100 \% \Delta \mathrm{DC}$ protocol that abolished slow waves by holding LP at its resting potential in TTX with no voltage step applied $(-59 \mathrm{mV}$ on average). TTX was applied at $t=$ -5 min to block spontaneous LP slow-wave and spiking activity, and the three voltage protocols were sequentially implemented as depicted in Figure $3 A$. LP $\mathrm{I}_{\mathrm{A}}$ was measured at time points indicated in Figure $3 A$ (red asterisks). Current traces from a single exemplar experiment in the absence of DA showed how LP $\mathrm{I}_{\mathrm{A}}$ was sculpted as duty cycle was sequentially altered (Fig. $3 B$ ). Stable, bidirectional changes in current density were elicited by 20 min alterations in duty cycle. As duty cycle was increased by 
A

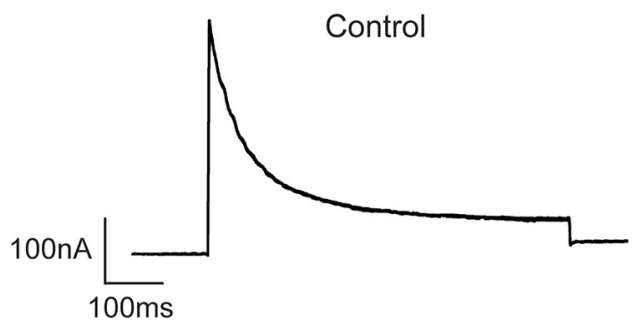

4AP

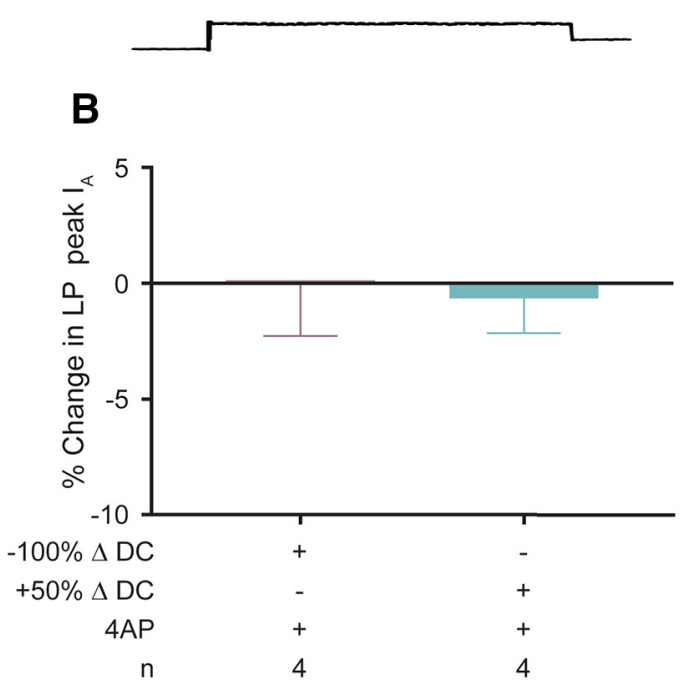

Figure 2. The difference current at $40 \mathrm{mV}$ largely represents $L P I_{A} \cdot A, A$ residual current remains when $L P I_{A}$ is blocked with $4 \mathrm{~mm} 4 A P$. Difference current traces elicited by a $40 \mathrm{mV}$ test pulse from a single LP sequentially superfused with saline containing TTX followed by TTX + 4AP. A small residual net outward current remained when $I_{A}$ was blocked. Calibration: $100 \mathrm{nA}$, $100 \mathrm{~ms}$. $\boldsymbol{B}$, The residual current is not regulated by activity. The experiments diagrammed in Figure $3 A$ were performed in $4 A P$. Changes in duty cycle did not alter the residual current.

switching from the $0 \% \Delta \mathrm{DC}$ protocol to the $50 \% \Delta \mathrm{DC}$ protocol, $\mathrm{I}_{\mathrm{A}}$ was reduced. Next, switching back to the $0 \% \Delta \mathrm{DC}$ protocol returned $\mathrm{I}_{\mathrm{A}}$ toward baseline. Finally, reducing duty cycle with the $-100 \% \Delta$ DC protocol increased $\mathrm{I}_{\mathrm{A}}$. These data illustrated that LP $\mathrm{I}_{\mathrm{A}}$ was continuously regulated by duty cycle. Results were the same regardless of the order of the voltage step protocols. The percent change in peak $\mathrm{I}_{\mathrm{A}}$ resulting from the $-100 \% \Delta \mathrm{DC}$ and $50 \% \Delta \mathrm{DC}$ protocols relative to the preceding $0 \% \Delta \mathrm{DC}$ voltage protocol was plotted (Fig. $3 C$ ). Reducing duty cycle with the $-100 \% \Delta \mathrm{DC}$ protocol produced an average $13 \pm 2.2 \%$ increase in peak LP $\mathrm{I}_{\mathrm{A}}$, whereas increasing duty cycle with the $50 \% \Delta \mathrm{DC}$ protocol produced an average $14 \pm 3.3 \%$ decrease in peak $L P I_{A}$. Preliminary studies showed the same effect was obtained when duty cycle was increased by reducing period rather than increasing plateau duration $(n=3)$.

To test the effect of tonic $5 \mathrm{~nm}$ DA, a separate series of experiments was performed exactly as described previously (Fig. $3 A$ ), except that $5 \mathrm{~nm}$ DA was added to the superfusate immediately after the first measure of $\mathrm{LPI}_{\mathrm{A}}(t=0)$. Previous work showed that tonic $5 \mathrm{nM}$ DA does not obviously alter $\mathrm{LP} \mathrm{I}_{\mathrm{A}} \mathrm{G}_{\max }$ over the short-term (Zhang et al., 2010; Rodgers et al., 2013). The addition of $5 \mathrm{~nm}$ DA to the superfusate abolished duty cycle-dependent changes in LP $\mathrm{I}_{\mathrm{A}}$ (Fig. $3 C$ ).

In sum, LP duty cycle had similar effects on $\mathrm{I}_{\mathrm{A}}$ (Fig. 3) and $\mathrm{I}_{\mathrm{h}}$ (Krenz et al., 2015). Decreases in duty cycle enhanced the peak $I_{A}$ and $\mathrm{I}_{\mathrm{h}}$ over minutes, whereas increases in duty cycle diminished the peak $\mathrm{I}_{\mathrm{A}}$ and $\mathrm{I}_{\mathrm{h}}$. Interestingly, the gating effect of tonic $5 \mathrm{nM} \mathrm{DA}$ was opposite for the two currents. Tonic 5 nM DA permitted duty cycle to regulate $\mathrm{LP}_{\mathrm{h}}$ (Krenz et al., 2015), but it prevented activity-dependent regulation of $\mathrm{LP}_{\mathrm{A}}$ (Fig. 3C).

\section{LP $I_{A}$ and $I_{h}$ are dynamically shaped by the balance between SUMO conjugation and deconjugation}

The role of SUMO in dynamically shaping LP ionic conductances was next investigated by examining the effect of enhancing or reducing SUMOylation during constant activity. Previous work showed that increasing the availability of activated SUMO peptide enhanced target protein SUMOylation (Parker et al., 2016), most likely by increasing the forward conjugation reaction (target + SUMO $\rightarrow$ SUMOylated target) and by reducing the reverse deconjugation reaction. Activated SUMO peptide concentration was increased in the LP neuron using bath application of membrane-permeable SUMO. Lobster SUMO cDNA was cloned (Fig. 4A), and two recombinant SUMO peptides were generated (Fig. 4B). Both peptides were tagged at their $\mathrm{N}$ terminus with an HIV-Tat sequence to allow cellular uptake (Fig. 4C) (Fawell et al., 1994). One version of the peptide, termed Tat-SUMO, represented the activated form of SUMO and possessed a C-terminal diglycine (GG); it required no further proteolytic processing before post-translational addition to a target protein (Mukhopadhyay and Dasso, 2007). For the second peptide, NC-Tat-SUMO, the two C-terminal glycines were replaced with alanines (AA). This version of SUMO could enter the cell but could not be conjugated to target proteins; thus, it served as a negative control. The experiment was as diagrammed in Figure 5A. A 30 min bath application of $100 \mathrm{nM}$ Tat-SUMO during a $0 \% \Delta \mathrm{DC}$ voltage protocol significantly decreased $\mathrm{LP} \mathrm{I}_{\mathrm{A}}$ by $10.1+1.4 \%$ and significantly increased LP $\mathrm{I}_{\mathrm{h}}$ by $11.2+1.5 \%$ (Fig. $5 B$ ). On the other hand, $100 \mathrm{~nm}$ NC-Tat-SUMO had no significant effect on LP $\mathrm{I}_{\mathrm{A}}$ or $\mathrm{I}_{\mathrm{h}}$ (Fig. $5 B$ ). Similarly, there were no significant changes in LP $\mathrm{I}_{\mathrm{A}}$ or $\mathrm{I}_{\mathrm{h}}$ in the absence of peptide (Wilcoxon test, $p>0.1, n=3$ each for $I_{h}$ and $I_{A}$ ).

Target protein SUMOylation was next reduced using cellpermeable anacardic acid. SUMO post-translational modifications are dynamic and depend on the balance between ongoing conjugation and deconjugation. Anacardic acid blocks one of the enzymes involved in SUMO conjugation (Fukuda et al., 2009). This shifts the balance of activity in favor of SUMO deconjugation so target protein SUMOylation continuously decreases over time in anacardic acid. The experiment was as diagrammed in Figure $5 A$. After a $1 \mathrm{~h}$ bath application of $10 \mu \mathrm{M}$ anacardic acid during a $0 \% \Delta \mathrm{DC}$ voltage protocol, the mean peak $\mathrm{I}_{\mathrm{A}}$ significantly increased by $9.7 \pm 2.8 \%$ and the mean $L_{P} I_{h} G_{\max }$ significantly decreased by $14 \pm 4.5 \%$ (Fig. $5 C$ ).

In sum, the data showed that $\mathrm{LP}_{\mathrm{A}}$ and $\mathrm{I}_{\mathrm{h}}$ were dynamically shaped by the balance between the ongoing processes of SUMO conjugation and deconjugation. SUMOylation had contrasting effects on the two conductances. Enhancing target protein SUMOylation simultaneously decreased LP $\mathrm{I}_{\mathrm{A}}$ and increased LP $\mathrm{I}_{\mathrm{h}}$. Reducing SUMOylation had the opposite effect.

\section{SUMO is necessary for activity-dependent changes in LP $I_{A}$} Our hypothesis is that changes in duty cycle adjust Kv4 channel SUMOylation to fine-tune LP $\mathrm{I}_{\mathrm{A}}$ amplitude. We next asked whether SUMOylation was necessary for LP $\mathrm{I}_{\mathrm{A}}$ activity dependence. Experiments similar to those diagrammed in Figure $3 \mathrm{~A}$ were repeated, except that Tat-SUMO or anacardic acid was added to the superfusate 30 or $60 \mathrm{~min}$ before the addition of TTX, 
A Experiment to determine $L P I_{A}$ activity-dependence

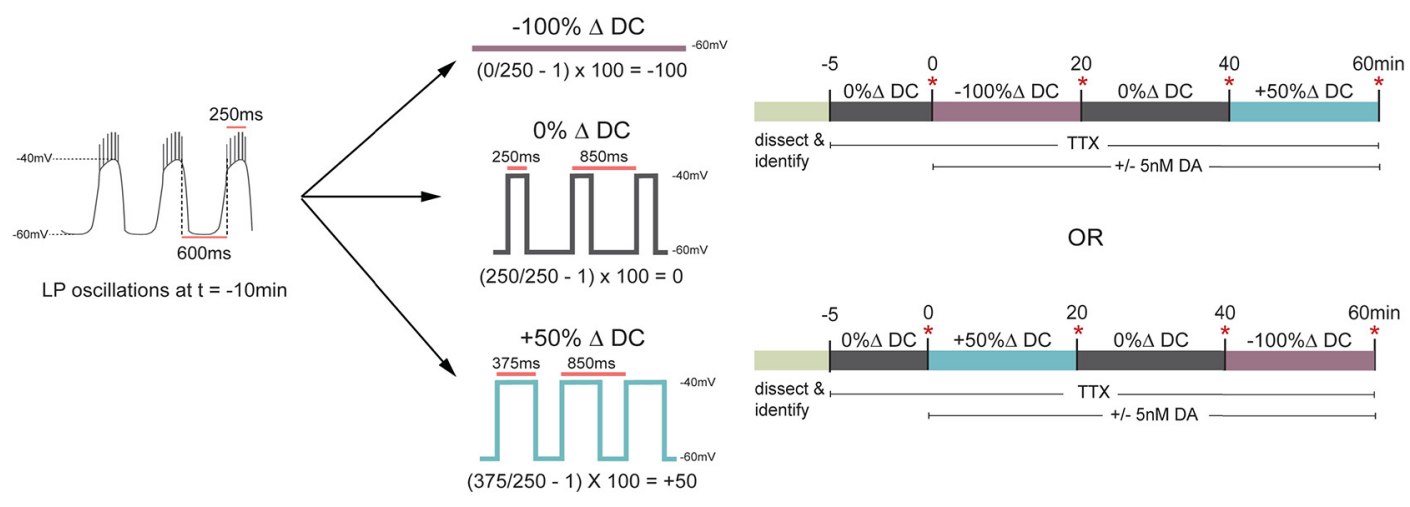

B Exemplar recordings of $L P I_{A}$ in the absence of $5 \mathrm{nM} D A$

C LP I $\mathrm{I}_{\mathrm{A}}$ is activity-dependent in the absence of $5 \mathrm{nM}$ DA

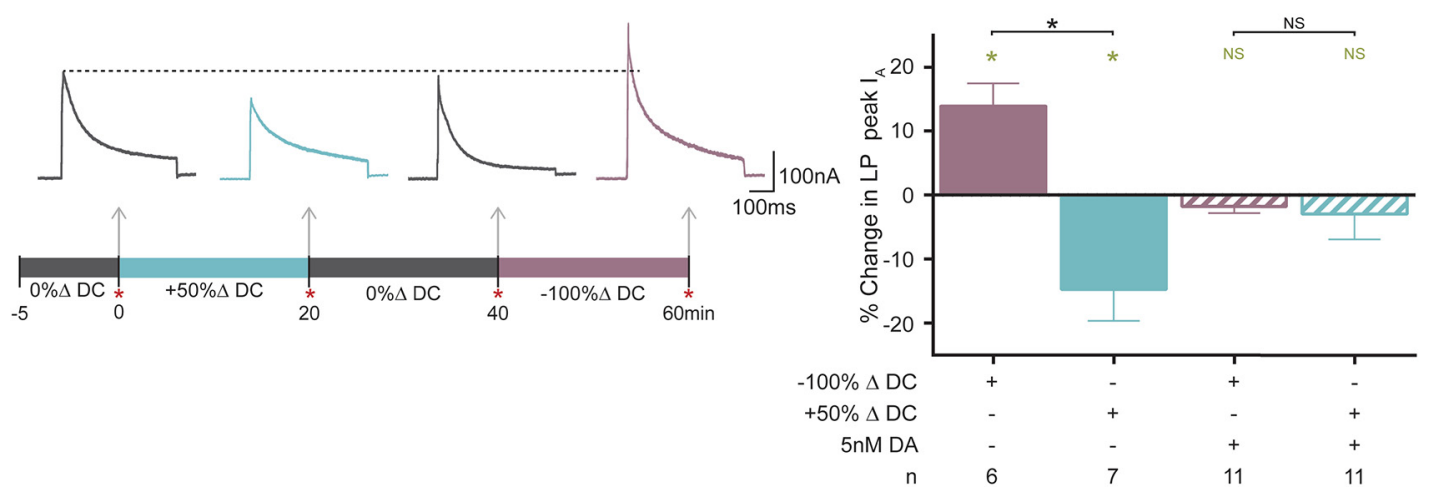

Figure 3. Duty cycle continuously regulates $L P I_{A}$ density, and tonic $5 \mathrm{~nm} D A$ gates this regulation. $A$, Experimental protocol for examining the activity dependence of $L P I_{A}$. Left, Diagram represents LP slow-wave activity at $t=-10 \mathrm{~min}$. Plateau duration $(250 \mathrm{~ms})$, peak $(-40 \mathrm{mV})$, and nadir ( $-60 \mathrm{mV})$ voltages, and cycle period $(850 \mathrm{~ms})$ were measured and used to create three voltage protocols: $-100 \%, 0 \%$, and $50 \% \Delta D C$. Voltage protocols were always specifically designed for each cell based on measurements from that cell. The protocols were used in the experiments diagramed on the right. At $t=-5 \mathrm{~min}$, TTX was bath-applied and the $0 \% \Delta \mathrm{DC}$ protocol was initiated. At $\mathrm{t}_{0}$, the current was measured (red asterisk) and one of the two series of voltage protocols shown was implemented in the presence or absence of $5 \mathrm{~nm}$ DA. Each voltage protocol lasted $20 \mathrm{~min}$, and the current was measured at the end of each protocol as indicated by red asterisks. The order of the voltage protocols was varied between experiments as shown in the two timelines. $B, L P I_{A}$ traces from a single exemplar experiment show that $L P I_{A}$ is continuously regulated by duty cycle. Difference current traces are shown for the indicated time points. Calibration: $100 \mathrm{nA}, 100 \mathrm{~ms}$. The 20 min alterations in duty cycle produced bidirectional alterations in peak $\mathrm{I}_{A}$. $C$, Increasing $L P$ duty cycle reduces $I_{A^{\prime}}$ decreasing $L P$ duty cycle enhances $I_{A^{\prime}}$ and $5 \mathrm{~nm} D A$ blocks $L P I_{A}$ activity dependence. The experiment diagrammed in Figure $3 A$ was performed in the presence or absence of $5 \mathrm{~nm} D A$. Plot represents the mean percent change in peak $\mathrm{I}_{A}$ produced by a given change in duty cycle $\left[\left(\mathrm{t}_{60} / \mathrm{t}_{40}\right.\right.$ or $\left.\left.\mathrm{t}_{20} / \mathrm{t}_{0}\right)-1 \times 100\right]$. Green asterisks indicate significant difference within a treatment group using paired $t$ tests $\left(\mathrm{t}_{0} \mathrm{vst}_{20}\right.$, ort $\left._{40} \mathrm{vs}_{60} ; p \leq 0.05\right)$. Black asterisks indicate significant differences using a one-way ANOVA with Bonferroni's multiple comparisons post hoc tests to compare selected pairs, as indicated $\left(F_{(3,31)}=8.512 ; p=0.0003\right)$.

respectively, and remained throughout the experiment. Enhancing SUMOylation for $30 \mathrm{~min}$ before changing activity prevented the decrease in $\mathrm{LP} \mathrm{I}_{\mathrm{A}}$ normally elicited by the $50 \% \Delta \mathrm{DC}$ voltage protocol (Fig. 6B). Enhanced SUMOylation decreased $\mathrm{I}_{\mathrm{A}}$ in the absence of a change in activity (Fig. 5B). Thus, enhanced SUMOylation both mimicked and occluded the activitydependent decrease in $\mathrm{LP} \mathrm{I}_{\mathrm{A}}$ elicited by the $50 \% \Delta \mathrm{DC}$ protocol. On the other hand, enhanced SUMOylation had no effect on the increase in $\mathrm{LP} \mathrm{I}_{\mathrm{A}}$ elicited by the $-100 \% \Delta$ DC protocol (Fig. $6 B$ ), which was consistent with the idea that the increase was due to deconjugation of SUMO.

We next examined the effect of anacardic acid, which blocks SUMO conjugation and promotes deconjugation. After a $1 \mathrm{~h}$ bath application of anacardic acid, subsequent changes in duty cycle could no longer elicit changes in the peak $\mathrm{I}_{\mathrm{A}}$ (Fig. 6C). Anacardic acid increased LP $\mathrm{I}_{\mathrm{A}}$ in the absence of a change in activity (Fig. $5 C$ ). Thus, the $1 \mathrm{~h}$ anacardic acid application both mimicked and occluded the increase in LP $\mathrm{I}_{\mathrm{A}}$ elicited by the $-100 \% \Delta \mathrm{DC}$ protocol. It also blocked the decrease in $\mathrm{LP}_{\mathrm{A}}$ elicited by the $50 \% \Delta \mathrm{DC}$ protocol, which was consistent with the idea that SUMO conjugation was necessary for that decrease. These data suggested that dynamic changes in SUMOylation were necessary for activity-dependent changes in peak LP $\mathrm{I}_{\mathrm{A}}$.

\section{Tonic 5 nM DA prevents SUMO deconjugation from and conjugation to the target protein(s) conferring $L P I_{A}$ activity dependence}

Thus far, the data are consistent with our hypothesis that duty cycle regulates the level to which LP Kv4 channels are decorated with SUMO, which in turn influences $\mathrm{I}_{\mathrm{A}}$ amplitude. Tonic $5 \mathrm{nM}$ DA disabled $\mathrm{LP} \mathrm{I}_{\mathrm{A}}$ activity dependence (Fig. 3C). If our hypothesis is correct, then one possibility is that tonic $5 \mathrm{~nm}$ DA blocks the dynamic processes of SUMO conjugation and/or deconjugation associated with $\mathrm{LP} \mathrm{I}_{\mathrm{A}}$ activity dependence.

The experiment diagrammed in Figure $7 A$ tested whether DA could block the effect of anacardic acid, which promotes SUMO deconjugation and produces an increase in LP $\mathrm{I}_{\mathrm{A}}$ (Fig. $5 \mathrm{C}$ ) that mimics and occludes the effect of the $-100 \% \Delta \mathrm{DC}$ voltage protocol (Fig. 6C). LP was superfused with saline that did or did not contain $5 \mathrm{~nm} \mathrm{DA}$. After $5 \mathrm{~min}, \mathrm{LP} \mathrm{I}_{\mathrm{A}}$ was measured, anacardic acid 


\section{A Alignment of Lobster SUMO}

$\begin{aligned} \text { Pan SUMO } & \text { MSEEAKKE-----EKPTE---HINLKVLGQDGQVVHFKIK } 32 \\ \text { Mus SUMO } 1 & \text { MSDQEAKPSTEDLGDKKEG-EYIKLKVIGQDSSEIHFKVK } 39 \\ \text { Mus SUMO } 2 & \text { MADEKPKE-----GVKTENNDHINLKVAGQDGSVVQFKIK } 35 \\ \text { Mus SUMO } 3 & \text { MSEEKPKE-----GVKTEN-DHINLKVAGQDGSVVQFKIK } 34\end{aligned}$

Pan SUMO KHTSLKKLINAYCERSKLVQTTVRFRFDGQPISENDTPQG 72

Mus SUMO 1 MTTHLKKLKESYCQRQGVPMNSLRFLFEGQRIADNHTPKE 79

Mus SUMO 2 RHTPLSKLMKAYCERQGLSMRQIRFRFDGQPINETDTPAQ 75

Mus SUMO 3 RHTPLSKLMKAYCERQGLSMRQIRFRFDGQPINETDTPAQ 74

Pan SUMO LEMEDGDTIEVFQQQTGG------YYHHHLPQL 100

Mus SUMO 1 LGMEEEDVIEVYQEQTGG------------HSTV 101

Mus SUMO 2 LEMEDEDTIDVFQQQTGG--------------VY 95

Mus SUMO 3 LEMEDEDTIDVFQQQTGGSASRGSVPTPNRCPDLCY 110

B Tat-SUMO construct

\begin{tabular}{|ccccc|}
\hline 6xHis & Tat Domain & HA & Active Pan SUMO & GG \\
\hline \multicolumn{7}{c}{ NC-Tat-SUMO construct } & & \\
\hline 6xHis & Tat Domain & HA & Non-conjugatable Pan SUMO & AA \\
\hline
\end{tabular}

C Test of Tat-SUMO uptake

OnM Tat-SUMO
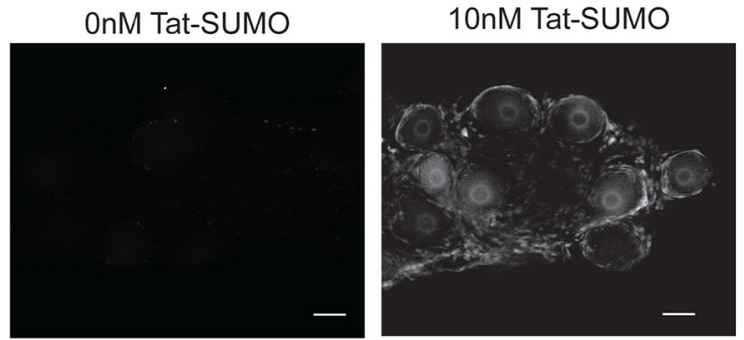

100nM Tat-SUMO

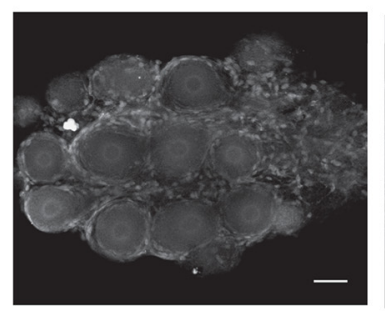

$1 \mu \mathrm{M}$ Tat-SUMO

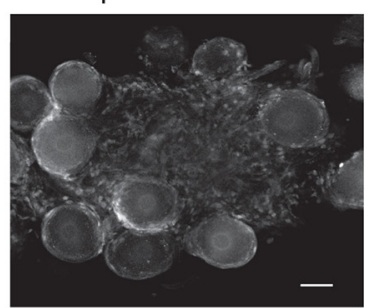

Figure 4. Generating a tool to globally increase SUMOylation in LP. A, Comparison of lobster and mouse SUMOs. SUMO was cloned from spiny lobster, $P$. interruptus (GenBank accession: MF770707). Aligning the amino acid sequence showed that Panulirus SUMO shares $\sim 47 \%$ identity with mouse SUM01(GenBank accession: P63166) and $\sim 67 \%$ identity with mouse SUM02 and 3 (GenBank accession: P61957 and Q92172 respectively). Highlighted areas represent regions of conservation. Arrowhead indicates the site where SUM0 is cleaved to generate the mature peptide ending in diglycine. B, Tat-HA-His-SUMO construct. Activated Panulirus SUMO (C-terminal diglycine) was subcloned into a Tat-HA-His vector. As a negative control, a plasmid encoding a nonconjugatable Tat-SUMO (NC-Tat-SUMO) ending in a dialanine was also constructed. C, Tat-SUMO is efficiently taken up by pyloric neurons. Recombinant Tat-SUMO peptide was isolated using the plasmid in Figure $4 B$ and standard techniques as detailed in Materials and Methods. Varying concentrations of the peptide ( $0 \mathrm{~nm}, 10 \mathrm{~nm}, 100 \mathrm{nM}$, and $1 \mu \mathrm{M})$ were bath-applied to STG, which contain the pyloric circuit. STGs were fixed and immunostained with anti-Tat. Tat immunoreactivity was not visible in the absence of bath-applied Tat-SUMO (0 nM). When Tat-SUMO was bath-applied, immunoreactivity was clearly visible in the nucleus and cytoplasm of the neurons as well as in the surrounding glial cells. Tat-SUMO uptake appeared to increase in a concentrationdependent manner; $100 \mathrm{~nm}$ appeared to be optimal with no detectable improvement at a higher concentration. Scale bar, $50 \mu \mathrm{m}$.

was added to the superfusate, and a $0 \% \Delta \mathrm{DC}$ voltage protocol was implemented. LP I $\mathrm{I}_{\mathrm{A}}$ was remeasured after $1 \mathrm{~h}$. Tonic $5 \mathrm{~nm} \mathrm{DA}$ blocked the effect of anacardic acid on LP $\mathrm{I}_{\mathrm{A}}$ (Fig. 7A).

The experiment diagrammed in Figure $7 B$ tested whether DA could block the effect of Tat-SUMO, which promotes SUMO conjugation and produces a reduction in peak $\mathrm{LP} \mathrm{I}_{\mathrm{A}}$ (Fig. $5 \mathrm{~B}$ ) that mimics and occludes the effect of the $50 \% \Delta \mathrm{DC}$ voltage protocol (Fig. $6 B)$. The preparation was superfused with saline that did or did not contain $5 \mathrm{~nm} \mathrm{DA}$. After $5 \mathrm{~min}, \mathrm{LP} \mathrm{I}_{\mathrm{A}}$ was measured with TEVC, Tat-SUMO or NC-Tat-SUMO was added to the superfusate, and a
$0 \% \Delta \mathrm{DC}$ voltage protocol was implemented. $\mathrm{I}_{\mathrm{A}}$ was remeasured every 10 min throughout the SUMO wash-in. The data showed that Tat-SUMO had no effect on $\mathrm{LP} \mathrm{I}_{\mathrm{A}}$ in the presence of $5 \mathrm{nM}$ DA.

In sum, the data indicated that DA can prevent the changes in SUMOylation that are necessary for $\mathrm{LP} \mathrm{I}_{\mathrm{A}}$ activity dependence.

Dynamic SUMOylation is also necessary for DA-enabled LP $I_{h}$ activity dependence

Alterations in duty cycle produced changes in $L P I_{h} G_{\max }$ that were very similar to those observed for peak $\mathrm{I}_{\mathrm{A}}$; however, $\mathrm{I}_{\mathrm{h}}$ ac- 
A Experimental Protocol

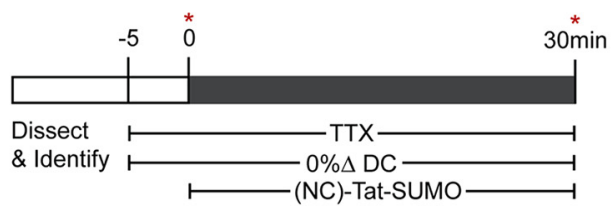

B Effect of Tat-SUMO on LP $I_{A}$ and $I_{h}$

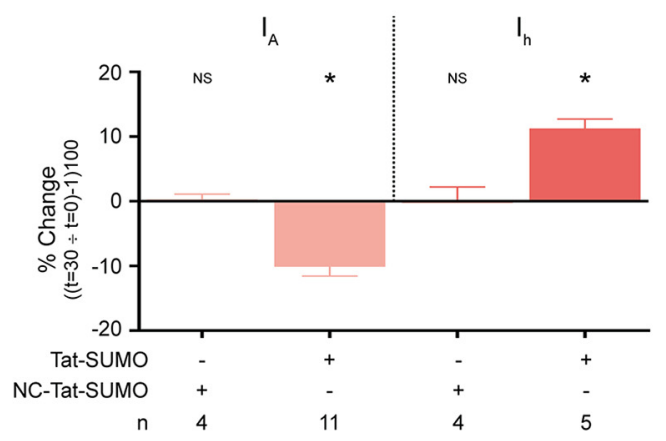

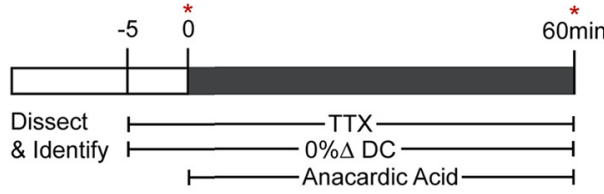

C Effect of Anacardic Acid on $L P I_{A}$ and $I_{h}$

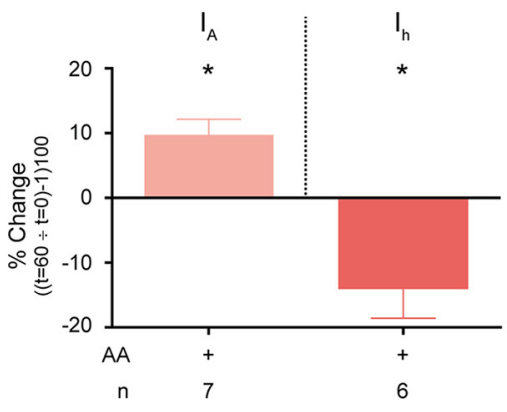

Figure 5. Dynamic SUMOylation continuously sculpts $\mathrm{LPI}_{\mathrm{A}}$ and $\mathrm{I}_{\mathrm{h}}$ during constant activity. $A$, Experimental protocols. Diagrams represent the experiments used to obtain the data presented in $\boldsymbol{B}$ and $\boldsymbol{C}$. Red asterisks indicate points where either $L P I_{A}$ or $I_{h}$ was measured. $\boldsymbol{B}$, Increased SUMOylation reduced $L P I_{A}$ and enhanced $L P I_{h}$. Plot represents the mean percent change in each current $\left[\left(t_{30} / t_{0}\right)-1 \times 100\right]$ elicited by a 30 min bath application of Tat-SUMO or NC-Tat-SUMO. *Significantly different using a paired $t$ test $\left(I_{A^{\prime}}, p=0.0031 ; I_{h^{\prime}} p=0.0007\right)$. C, Decreased SUM0ylation increased $L P I_{A}$ and reduced $L P I_{h}$. Plot represents the mean percent change in each current $\left[\left(t_{60} / t_{0}\right)-1 \times 100\right]$ elicited by a 60 min bath application of anacardic acid (AA). ${ }^{*}$ Significantly different using a paired $t$ test $\left(I_{A^{\prime}}, p=0.0239 ; I_{h^{\prime}} p=0.0487\right)$.

A Activity-dependent changes in $\mathrm{LP} \mathrm{I}_{\mathrm{A}}$
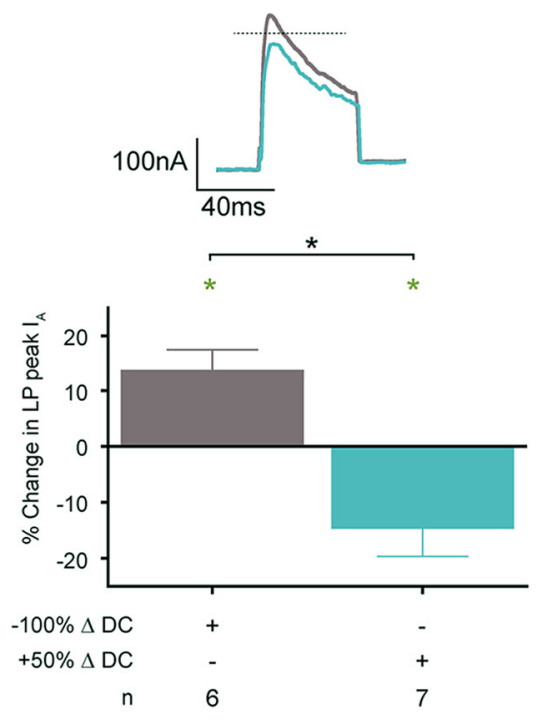

B Activity-dependent changes after Tat-SUMO wash-in
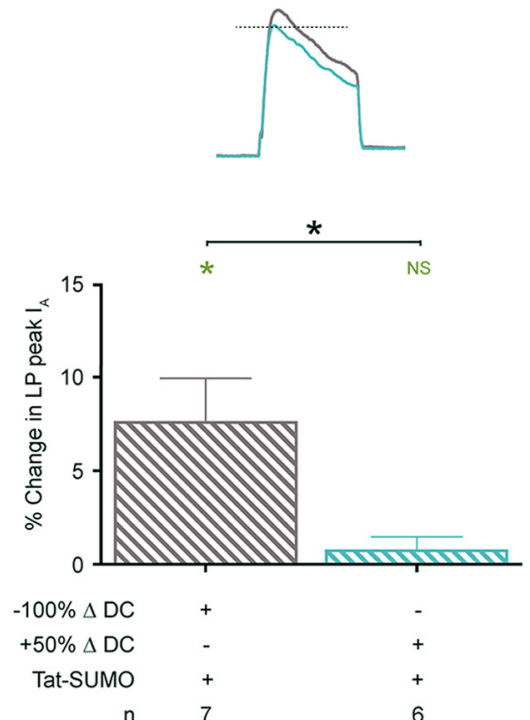

C Activity-dependent changes after anacardic acid wash-in
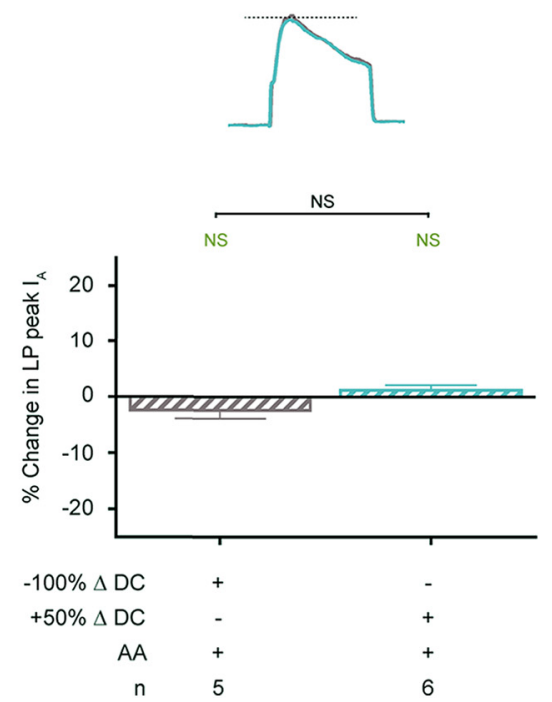

Figure 6. Dynamic SUMOylation is necessary for LPI $\mathrm{I}_{A}$ activity dependence. The effect of SUMOylation on $\mathrm{I}_{A}$ activity dependence was determined. $\boldsymbol{A}$, Results of experiments implementing the standard series of voltage protocols described for Figure $3 A$ are shown for comparison. $B, C$, To determine whether a given change in SUMOylation blocked or occluded $L P I_{A}$ activity dependence, experiments described for Figure $3 A$ were repeated after a 30 min Tat-SUMO (B) or 60 min anacardic acid (AA) wash-in (C). Top, 0verlay of difference current traces elicited by the $-100 \% \triangle D C$ (purple) and $50 \% \triangle D C$ (cyan) protocols from a single representative experiment. Calibration: $100 \mathrm{nA}, 40 \mathrm{~ms}$. Dotted line indicates the peak current elicited by the preceding $0 \% \triangle D C$ protocol. In the

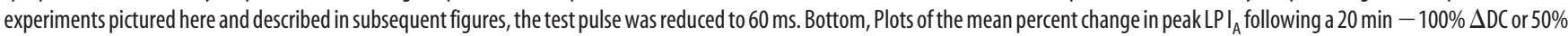
$\Delta D C$ protocol relative to the preceding $0 \% \triangle D C$ protocol. $B$, Green asterisks indicate significant difference between the $-100 \%$ or $50 \% \Delta D C$ and its preceding $0 \% \Delta D C$ protocol using a paired $t$ test $(p<0.05)$. Black asterisks indicate significant difference between treatment groups using an unpaired $t$ test $(p=0.0218)$.

tivity dependence only occurred in the presence of tonic $5 \mathrm{~nm}$ DA (Krenz et al., 2015). Here we tested the hypothesis that DA enables LP $\mathrm{I}_{\mathrm{h}}$ activity dependence by permitting SUMO conjugation to and deconjugation from HCN channels.

Bath application of 5 nм DA permitted duty cycle-dependent regulation of $L P \mathrm{I}_{\mathrm{h}}$ by eliciting two simultaneous PKA-dependent events that could be pharmacologically uncoupled. Event 1 was a $\sim 12 \%$ activity-independent increase in $\mathrm{LP} \mathrm{I}_{\mathrm{h}} \mathrm{G}_{\max }$ with a time constant $(\tau)$ of $\sim 10 \mathrm{~min}$. Event 2 was a calcineurin-mediated decrease in $L P I_{h} G_{\max }$. Bidirectional activity dependence was achieved through the additive effects of Events 1 and 2. Because Event 1 was activity-independent, it was constant in all three voltage 
A Tonic DA blocks the effect of SUMO deconjugation on $\mathrm{LP} \mathrm{I}_{\mathrm{A}}$
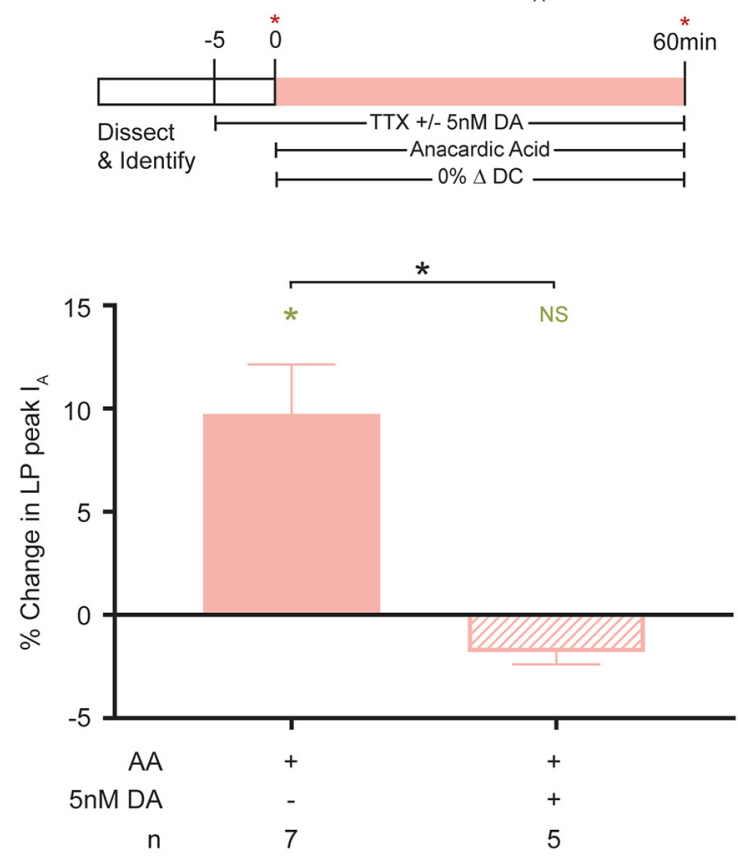

B Tonic DA blocks the effect of SUMO conjugation on LP I
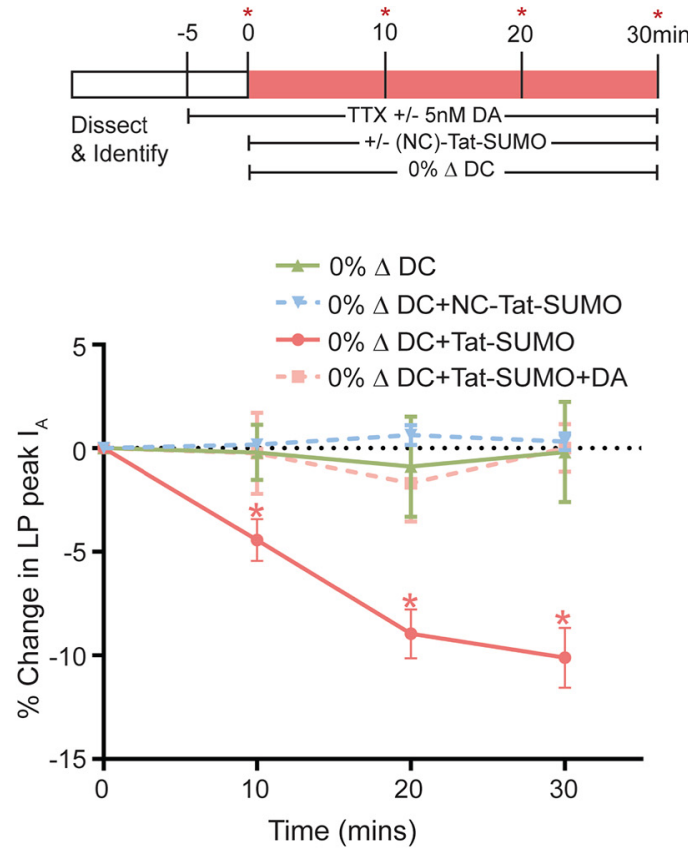

Figure 7. Tonic $5 \mathrm{~nm}$ DA blocks the dynamic SUMOylation necessary for $\mathrm{LPI}_{\mathrm{A}}$ activity dependence. $A$, Tonic nM DA blocks the SUM0 deconjugation associated with $\mathrm{I}_{\mathrm{A}}$ activity dependence. To determine whether DA could block SUMO deconjugation, the preparation was or was not superfused with $5 \mathrm{~nm} D A$ before the addition of anacardic acid (AA) during a $0 \% \triangle D C$ voltage protocol. Top,

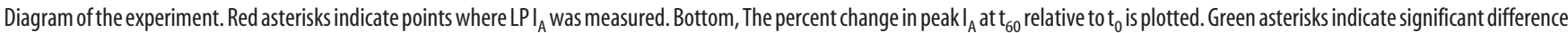
between $\mathrm{t}_{0}$ and $\mathrm{t}_{60}$ using a paired $t$ test $(p=0.0239$ ). Black asterisks indicate significant difference between treatment groups using an unpaired $t$ test ( $p=0.0027$ ). $\boldsymbol{B}$, Tonic $5 \mathrm{~nm}$ DA blocks the SUMO conjugation associated with $\mathrm{I}_{\mathrm{A}}$ activity dependence. To determine whether DA could block SUMO conjugation, the preparation was superfused with $5 \mathrm{~nm}$ DA before the addition of Tat-SUMO during a $0 \% \Delta D C$ voltage protocol. Top, Experiment is diagrammed. Red asterisks indicate points where $\mathrm{LPI}_{\mathrm{A}}$ was measured. Bottom, The percent change in peak $\mathrm{I}_{\mathrm{A}}$ at $\mathrm{t}_{10}$, $\mathrm{t}_{20}$, and $\mathrm{t}_{30}$ relative to $\mathrm{t}_{0}$ is plotted. Asterisks indicate significantly different using repeated-measures ANOVA with Dunnett's post hoc that compared each data point to $t_{0} ; 0 \% \Delta D C: F_{(4,12)}=0.1682 ; p=0.7381, n=5 ; 0 \%$ $\Delta \mathrm{DC}+$ Tat-SUM0: $F_{(10,30)}=13.65 ; p=0.0011, n=11 ; 0 \% \Delta \mathrm{DC}+$ Tat-SUMO + DA: $F_{(5,15)}=0.3438 ; p=0.7086, n=6 ; 0 \% \Delta \mathrm{DC}+\mathrm{NC}-\mathrm{Tat}-\mathrm{SUM} 0: F_{(3,9)}=0.7537 ; p=0.5060, n=4$.

protocols $\left(\sim 12 \%\right.$ increase in $\left.\mathrm{I}_{\mathrm{h}} \mathrm{G}_{\max }\right)$. On the other hand, Event 2 $\left(\mathrm{Ca}^{2+}\right.$-dependent decrease in $\left.\mathrm{I}_{\mathrm{h}} \mathrm{G}_{\max }\right)$ was minimal, maximal, and intermediate during the $-100 \%, 50 \%$, and $0 \% \Delta \mathrm{DC}$ protocols, respectively. The addition of Events 1 and 2 produced an increase and a decrease in $\mathrm{LP} \mathrm{I}_{\mathrm{h}} \mathrm{G}_{\max }$, respectively, during the $-100 \% \Delta \mathrm{DC}$ and $50 \% \Delta$ DC protocols relative to the $0 \% \Delta$ DC protocol.

The experiment to test whether Event 1 represented an activity-independent increase in $\mathrm{HCN}$ channel SUMOylation that occurred with a time constant of $\sim 10 \mathrm{~min}$ is diagrammed in Figure $8 \mathrm{~A}$ (left). Increasing SUMO conjugation with a $30 \mathrm{~min}$ wash-in of activated Tat-SUMO produced a stable and significant $11 \pm 1.5 \%$ increase in the average $L P I_{h} G_{\max }$ in the absence of DA with a mean $\tau$ of 7.1 min (Fig. $8 A$, right). The same result was obtained when the Tat-SUMO peptide was applied during a 30 min $-100 \% \Delta \mathrm{DC}$ or $0 \% \Delta \mathrm{DC}$ voltage protocol (Fig. $8 A$ ), indicating that an activity-independent process transduced enhanced activated SUMO availability into an increase in $L P \mathrm{I}_{\mathrm{h}} \mathrm{G}_{\max }$. Enhancing SUMO conjugation not only mimicked DA-enabled Event 1, but it also occluded it. After the $30 \mathrm{~min}$ Tat-SUMO wash-in was completed, $5 \mathrm{~nm}$ DA was or was not added to the superfusate, and the standard voltage protocols were implemented (Fig. 3). The DA-enabled activity-independent increase in $\mathrm{LP}_{\mathrm{h}}$ normally observed during the $-100 \% \Delta \mathrm{DC}$ protocol was now absent (Fig. $8 B$ ). On the other hand, Tat-SUMO had no effect on DA-enabled Event 2. An activity-dependent decrease in LP $\mathrm{I}_{\mathrm{h}}$ was still elicited by the $50 \% \Delta \mathrm{DC}$ protocol, but only in the presence of $5 \mathrm{~nm}$ DA (Fig. $8 B$ ).

Event 2 represents a calcineurin-mediated decrease in $L P I_{h}$, and its effect is largest during the $50 \% \Delta \mathrm{DC}$ protocol, where the duration of LP depolarization is maximal and presumably where $\mathrm{Ca}^{2+}$ levels are highest (Krenz et al., 2015). Reducing SUMOylation with anacardic acid also decreased $\mathrm{LP}_{\mathrm{h}} \mathrm{G}_{\max }$ (Fig. $5 C$ ), and to approximately the same extent as the $50 \% \Delta \mathrm{DC}$ protocol in the presence of DA (Krenz et al., 2015). We next asked whether anacardic acid occluded Event 2. Experiments similar to those diagrammed in Figure 3 were repeated, except that anacardic acid was or was not added to the superfusate for $1 \mathrm{~h}$ before the addition of TTX and remained in the superfusate throughout the experiment. After anacardic acid application, the $50 \% \Delta \mathrm{DC}$ protocol no longer elicited a decrease in $\mathrm{LP} \mathrm{I}_{\mathrm{h}} \mathrm{G}_{\max }$ in the presence of $5 \mathrm{~nm}$ DA (Fig. 8C). Thus, increasing SUMO deconjugation with anacardic acid both mimicked and occluded Event 2. Blocking SUMO conjugation with anacardic acid also blocked the increase in $\mathrm{LP}_{\mathrm{h}} \mathrm{G}_{\max }$ normally observed during the $-100 \% \Delta \mathrm{DC}$ voltage protocol, suggesting that an increase in SUMO conjugation underpins Event 1, which is consistent with our findings from experiments using TAT-SUMO (Fig. 8B).

In sum, the data presented here are consistent with the hypothesis that DA enables LP $\mathrm{I}_{\mathrm{h}}$ activity dependence by permitting activity-independent conjugation and activity-dependent deconjugation of SUMO.

\section{Lobster $\mathrm{HCN}$ and $\mathrm{Kv} 4$ channels are SUMOylated in vivo}

Our hypothesis predicts that LP duty cycle dynamically adjusts $\mathrm{HCN}$ and Kv4 channel SUMOylation levels to fine-tune $\mathrm{I}_{\mathrm{h}}$ and $\mathrm{I}_{\mathrm{A}}$ amplitudes, respectively. To determine whether lobster $\mathrm{HCN}$ and Kv4 channels were SUMOylated in vivo, we performed immunoprecipitation experiments with lobster CNS lysates followed by 


\section{A The effect of Tat-SUMO wash-in on LP $I_{h}$}
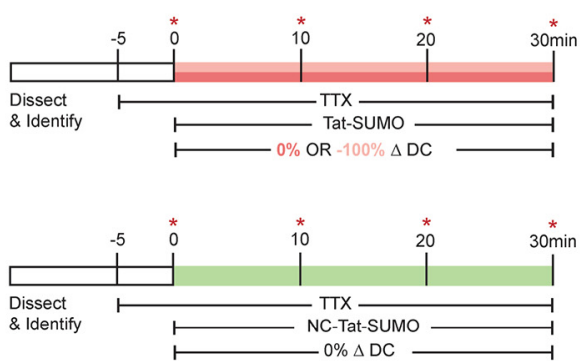

B Activity-dependent changes after Tat-SUMO wash-in

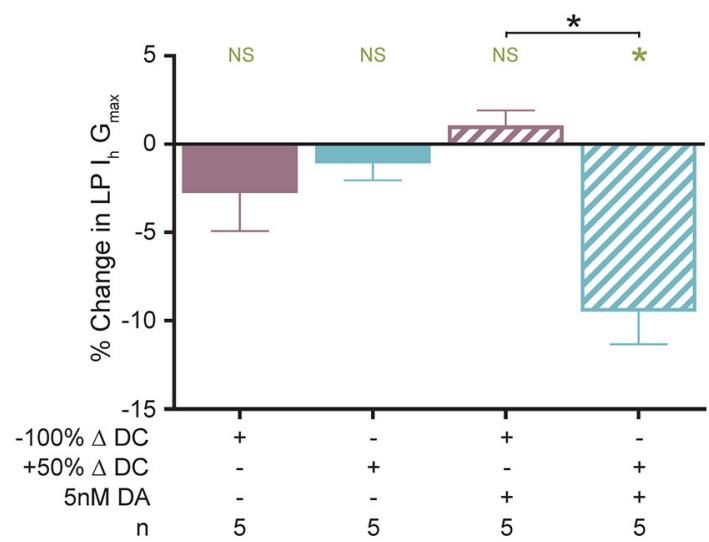

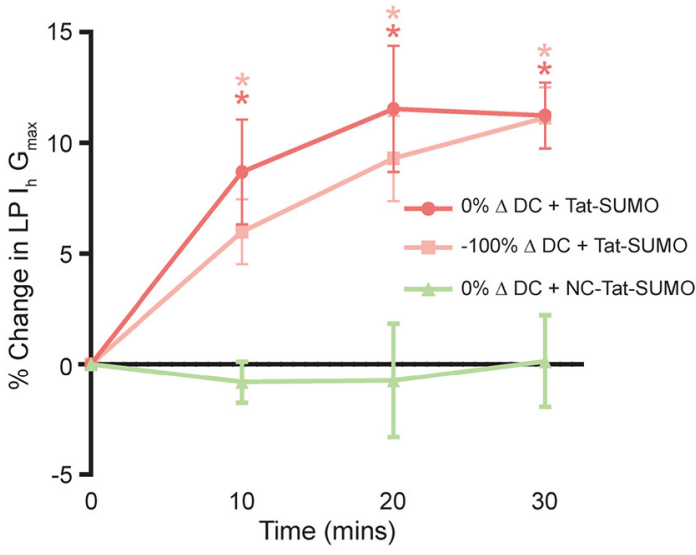

C Activity-dependent changes after anacardic acid wash-in

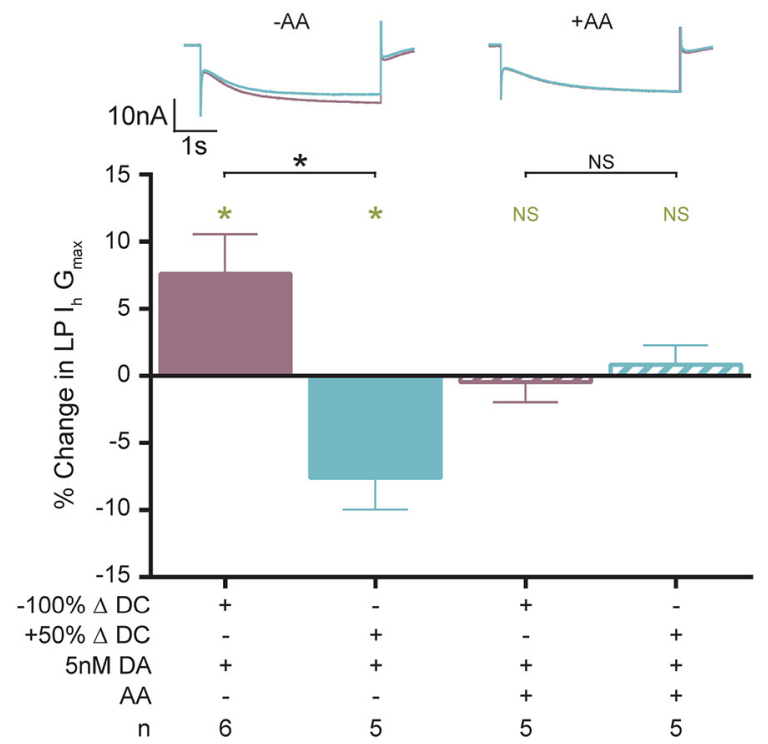

Figure 8. Dynamic SUMOylation is necessary for DA-enabled LPI $\mathrm{I}_{h}$ activity dependence. $A$, Enhancing SUMO conjugation mimics the increase in $\mathrm{I}_{h}$ associated with a decrease in duty cycle in the presence of $5 \mathrm{~nm} \mathrm{DA}$. LPI $\mathrm{h}_{\mathrm{h}}$ was measured before and during an (NC)-Tat-SUMO wash-in while a voltage protocol was implemented. Left, Diagrams represent the experiments. Red asterisks indicate points where $L P I_{h}$ was measured. Right, Plot represents the percent change in $L P I_{h} G_{\text {max }}$ at $t_{10}, t_{20}$, and $t_{30}$ relative to $t_{0}$. Asterisks indicate significantly different using repeated-measures ANOVAs with Dunnett's post hoc tests that compared each data point with $\mathrm{t}_{0} .0 \% \Delta \mathrm{DC}+$ Tat-SUMO: $F_{(4,12)}=21.03 ; p=0.0026, n=5 ;-100 \% \Delta \mathrm{DC}+$ Tat-SUM0: $F_{(5,15)}=23.01 ; p=0.0002, n=6$; $0 \% \Delta D C+N C$ Tat-SUMO: $F_{(3,9)}=0.5305 ; p=0.5792, n=4 . B$, Enhancing SUM0 conjugation occludes the DA-enabled, activity-dependent increase in $L P I_{h} G_{\max }$ but does not alter the DA-enabled activity-dependent decrease. After a 30 min activated Tat-SUMO wash-in, $\mathrm{LP}_{\mathrm{h}}$ was measured; DA was or was not added to the superfusate containing activated Tat-SUMO; and the standard series of voltage protocols was applied and $\mathrm{LPI}_{h}$ was measured at the end of each protocol as diagrammed in Figure $3 A$. The percent change in $L P I_{h} G_{\max }$ elicited by the $50 \% \Delta D C$ or $-100 \% \Delta D C$ protocol relative to the preceding $0 \% \Delta D C$ protocol was plotted. Green asterisk indicates significant difference using a paired $t$ test $(p=0.0074)$. Black asterisk indicates significant difference using a one-way ANOVA with Bonferroni's multiple comparisons post hoc tests to compare selected pairs, as indicated $\left(F_{(3,16)}=7.101 ; p=0.003\right)$. C, SUMO deconjugation mimics and occludes the decrease in $\mathrm{LPI}_{\mathrm{h}}$ elicited by an increase in duty cycle, and blocking SUMO conjugation abolishes the increase in $\mathrm{LPI}_{\mathrm{h}}$ elicited by a decrease in duty cycle. Anacardic acid (AA) was or was not washed in for $1 \mathrm{~h}$ and $L \mathrm{PI}_{\mathrm{h}}$ was measured. DA was added to the superfusate, the standard series of voltage protocols was applied, and $\mathrm{I}_{\mathrm{h}}$ was measured at the end of each protocol as diagrammed in Figure $3 A$. Top, Overlay of two current traces elicited by a hyperpolarizing test pulse to $-120 \mathrm{mV}$ from a representative experiment. Calibration: $10 \mathrm{nA}, 1 \mathrm{~s}$. Bottom, Plot of the percent change in $L P \mathrm{I}_{\mathrm{h}} \mathrm{G}_{\mathrm{max}}$ elicited by the $50 \% \Delta D C$ or $100 \% \Delta D C$ protocol relative to the preceding $0 \% \Delta D C$ protocol. Green asterisks indicate significant differences within a treatment group $(p<0.05)$ using a paired $t$ test $(-100 \%$ $\triangle \mathrm{DC}$ vs $0 \% \triangle \mathrm{DC} ; 50 \% \triangle \mathrm{DC}$ vs $0 \% \triangle \mathrm{DC}$ ). Black asterisk indicates significant difference between the four treatment groups using a one-way ANOVA with Bonferroni's multiple-comparisons post hoc tests to compare selected pairs, as indicated $\left(F_{(3,17)}=7.814 ; p=0.0017\right)$.

Western blotting. The specificity of the antibodies was first validated. Control experiments showed that an antibody against mouse SUMO1 (anti-SUMO1) recognized the recombinant lobster TAT-SUMO peptide (Fig. $9 A$ ), as well as SUMO and SUMOylated proteins in lobster nervous system protein lysates (Fig. 9B). A second series of experiments showed that a custommade, affinity-purified antibody against lobster $\mathrm{HCN}$ channels (anti-HCN) recognized a lobster HCN-GFP fusion protein stably expressed in HEK cells (Fig. 9C). A third series of control experiments showed that a custom-made, affinity-purified antibody against lobster Kv4 channels (anti-ORFJ) and a previously validated antibody against a conserved region of the lobster Kv4 protein (Baro et al., 2000) recognized the same $\sim 75 \mathrm{kDa}$ band on Western blots containing lobster nervous system protein lysates (Fig. 9D). Thus, anti-ORFJ specifically recognizes lobster Kv4 channels. 
A Anti-SUMO1 recognizes lobster Tat-SUMO

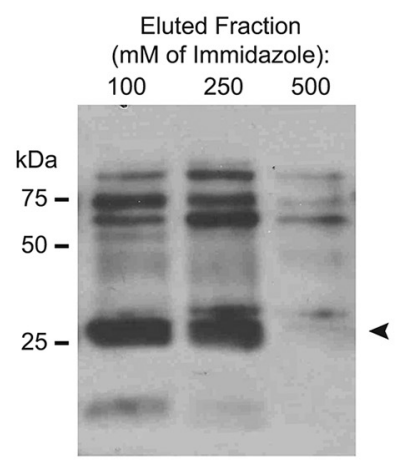

C Lobster HCN antibody reconizes GFP tagged Lobster HCN
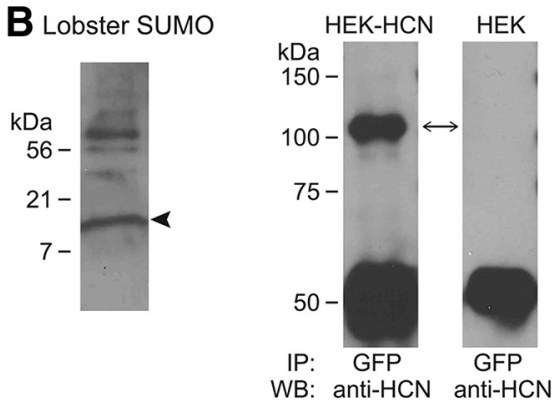

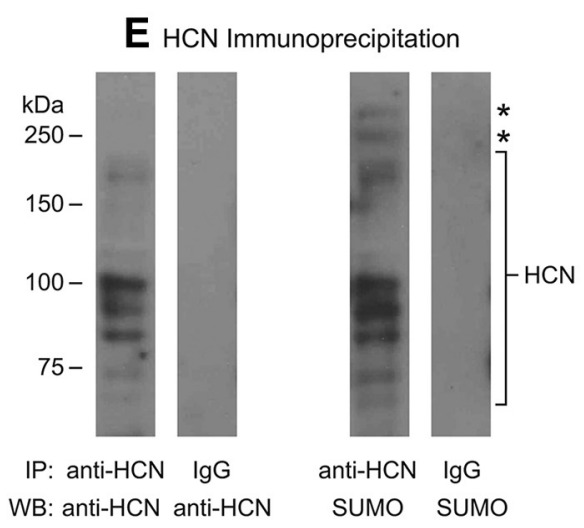

D Lobster Kv4 Antibody

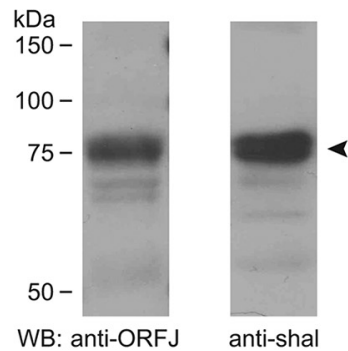

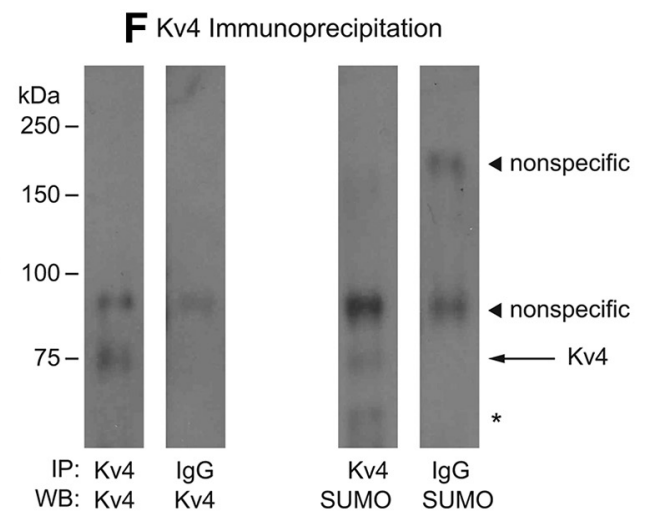

Figure 9. P. interruptus HCN and Kv4 channels are SUMOylated. A, Anti-SUMO1 recognizes a recombinant lobster SUMO peptide. Recombinant lobster Tat-SUMO peptide was purified using Ni-NTA agarose resin and was eluted from the resin with incrementally increasing concentrations of imidazole $(100,250,500 \mathrm{~mm})$. Eluted fractions were used in Western blot experiments with anti-SUM01. The strong band at $\sim 25 \mathrm{kDa}$ in the 100 and $250 \mathrm{~mm}$ fractions represents Tat-SUMO peptide (arrow). B, Anti-SUM01 recognizes lobster SUM0 and SUMOylated lobster proteins. A Western blot containing lobster nervous system protein lysate was probed with anti-SUM01. The antibody successfully recognized the $\sim 11 \mathrm{kDa}$ free SUMO (arrowhead) in addition to other higher molecular weight bands representing SUMOylated lobster proteins. C, Immunoprecipitation experiments (IPs) were performed using anti-GFP and lysates from HEK cells that did (HEK-HCN) or did not (HEK) express a lobster HCN channel fused to GFP. Western blots (WB) containing the IP products were probed with anti-HCN. The strong signal at $\sim 110 \mathrm{kDa}$ represents the channel (double-head arrow). D, Anti-ORFJ recognizes the lobster Kv4 channel in lobster nervous system lysates. WB-containing lobster nervous system protein lysates were probed with anti-ORFJ or anti-shal, a previously validated antibody against the lobster Kv4 channel. Both antibodies recognized the same $\sim 75 \mathrm{kDa}$ band (arrow). E, Lobster HCN channels are SUMOylated in vivo. Lysates prepared from lobster nervous system tissue were used in IP experiments with anti-HCN or IgG (negative control). WB containing the IP products were probed with anti-HCN or anti-SUM01 as indicated. The SUMO modified HCN channels are bracketed. Asterisks indicate unknown SUMOylated proteins that potentially interact with the immunoprecipitated channel. $\boldsymbol{F}$, Lobster Kv4 channels are SUMOylated in vivo. Lobster nervous system lysates were used in IP experiments with anti-ORF-J or lgG (negative control). WB containing the IP products were probed with anti-ORFJ or anti-SUM01 as indicated. Arrow indicates the SUMO modified Kv 4 channels. Asterisk indicates an unknown SUMOylated protein that potentially interacts with the immunoprecipitated channel. Arrowheads indicate proteins that nonspecifically associate with lgG in the IP reactions. Immunoprecipitation experiments were repeated with at least 3 animals for each channel.

After validating the specificity of all antibodies, IP experiments were performed using anti-HCN, anti-ORF-J and IgG (negative control). Western blots containing the resulting immunoprecipitation products were probed with anti-SUMO1 and either anti-HCN (Fig. 9A) or anti-ORFJ (Fig. 9B). Both HCN and $\mathrm{Kv} 4$ channels appeared to be SUMOylated in vivo. The anti-HCN and anti-SUMO1 antibodies recognized multiple matching bands in the anti-HCN but not the IgG immunoprecipitation product. The bands were in the correct size range for posttranslationally modified alternately spliced $\mathrm{HCN}$ channel isoforms (Ouyang et al., 2007). The anti-ORFJ and anti-SUMO1 antibodies recognized a single, appropriately sized, matching band in the anti-ORFJ but not the IgG IP product. The SUMO signal was weak compared with the Kv4 signal. This may indicate that steady-state levels of Kv4 SUMOylation are low. The antiSUMO1 antibody recognized additional bands not recognized by the channel antibodies in both the anti-HCN and anti-ORFJ but not the IgG IP products. These may represent SUMOylated proteins that noncovalently interact with the channels. Both antibodies also recognized proteins that nonspecifically associate with IgG antibodies. In sum, the data are consistent with our hypothesis that lobster Kv4 and HCN channels are SUMOylated in vivo.

\section{Dynamic SUMOylation is necessary for duty cycle and phase recovery in $5 \mu \mathrm{M}$ DA}

If SUMOylation-mediated, duty cycle-dependent regulation of $\mathrm{I}_{\mathrm{A}}$ and $\mathrm{I}_{\mathrm{h}}$ contributes to a feedback mechanism that maintains duty cycle, then when LP cycle frequency is continuously increased, duty cycle should initially be disrupted but should recover over time, and blocking dynamic SUMOylation with anacardic acid should prevent this recovery. Previous studies showed that $100 \mu \mathrm{M}$ DA altered pyloric network output by directly modulating synaptic properties and ionic conductances in all pyloric neurons (Harris-Warrick et al., 1998; Harris-Warrick, 2011), and $5 \mu \mathrm{M}$ DA produced similar changes in output that were of a smaller magnitude (Rodgers et al., 2011). Therefore, bath application of $5 \mu \mathrm{M}$ DA to the STG should both modulate LP conductances and gate their activity dependence; the latter can be considered a metamodulatory effect (Krenz et al., 2015).

In the next set of experiments, the preparation was superfused with $5 \mu \mathrm{M}$ DA with or without anacardic acid, and LP activity was 


\section{A Motor output in $5 \mu \mathrm{M}$ DA}

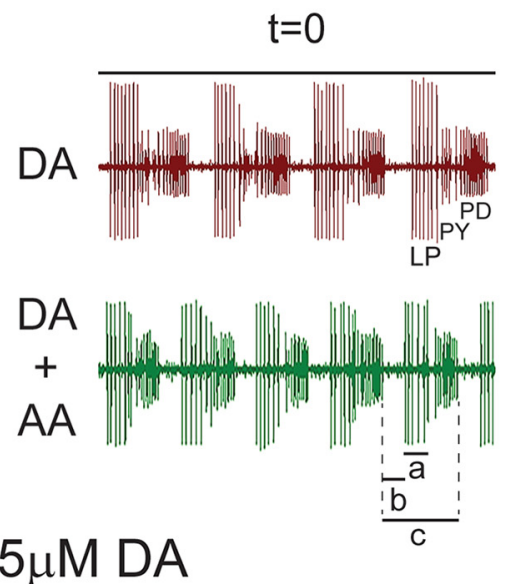

B $5 \mu \mathrm{M} \mathrm{DA}$

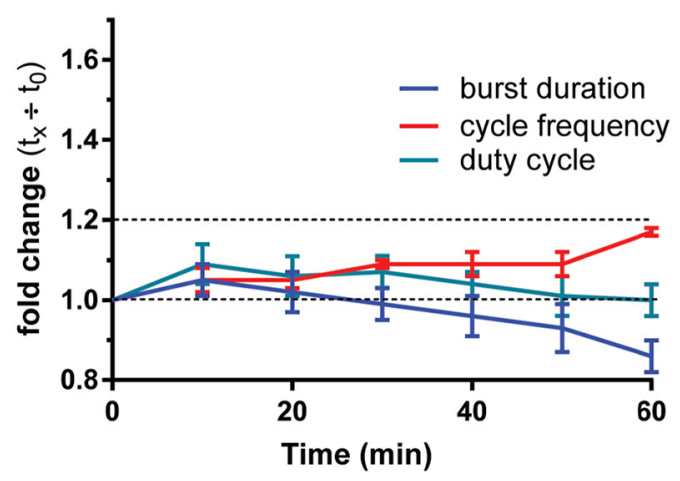

D $10 \mu \mathrm{M}$ AA

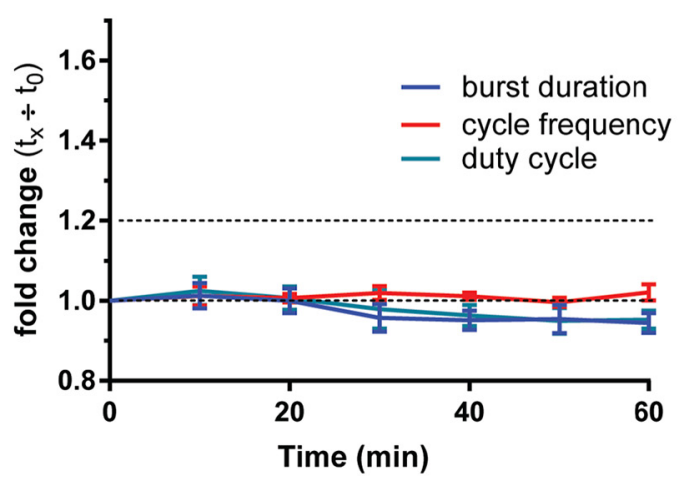

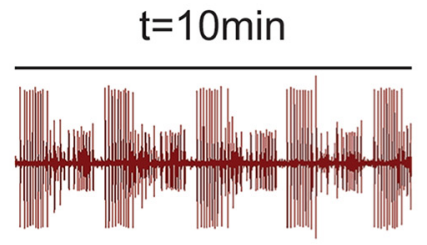
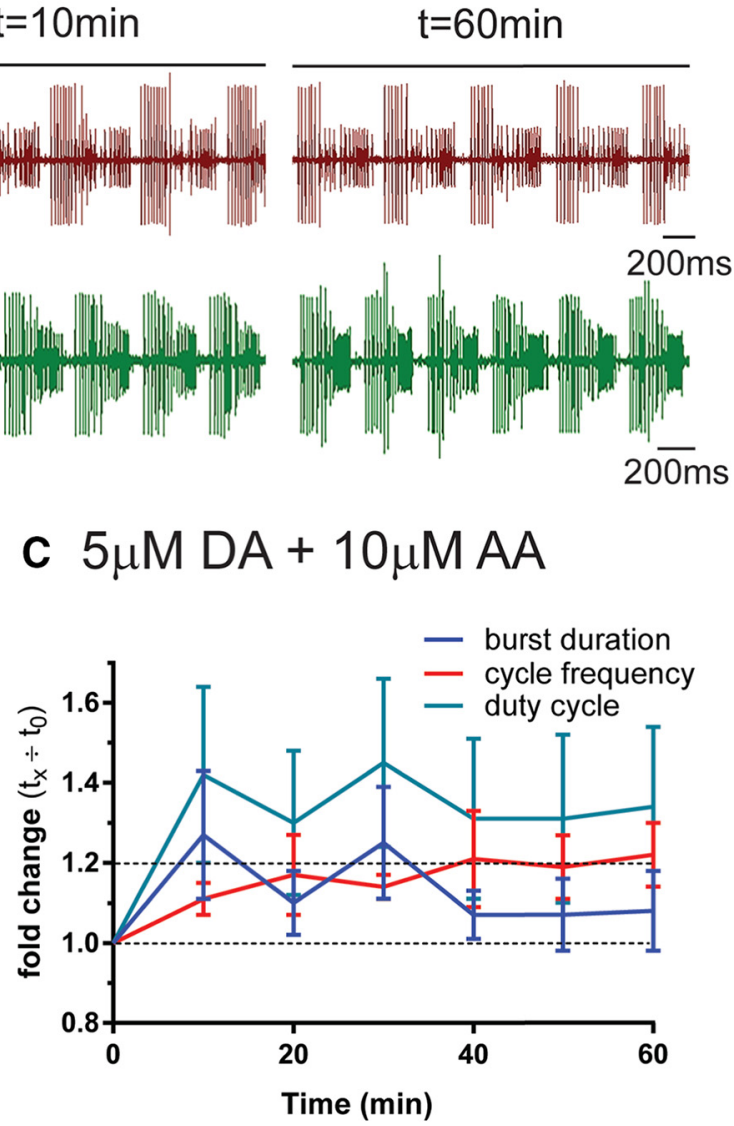

E Phase

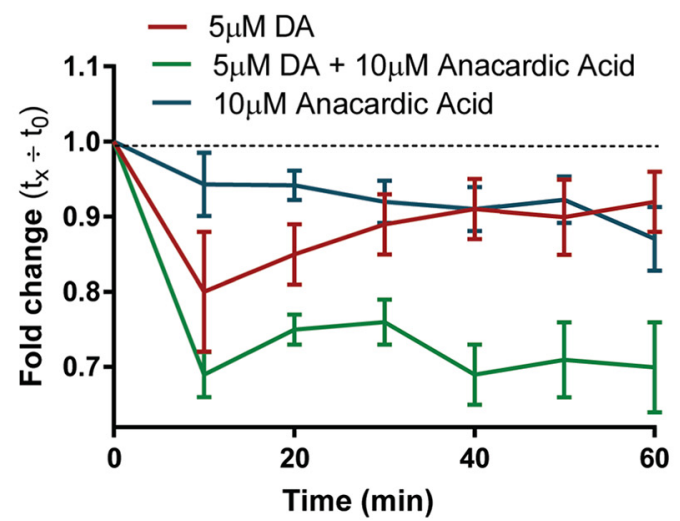

Figure 10. Dynamic SUMOylation is necessary for activity homeostasis. A, Blocking dynamic SUMOylation with anacardic acid (AA) alters circuit output in $5 \mu \mathrm{m}$ DA. Preparations were continuously superfused with $5 \mu \mathrm{m} \mathrm{DA}, 10 \mu \mathrm{m} \mathrm{AA}$, or both. Extracellular recordings from the lateral ventricular nerve (/vn) were maintained throughout the experiment, and three time points from a representative experiment in DA (top) or DA + AA (bottom) are shown. The continuous, spontaneous triphasic output of the pyloric circuit is represented by the rhythmic spiking of three cell types on the /vn: LP, pyloric constrictor (PY), and pyloric dilator (PD). The /vn recordings were used to measure LP burst duration (a), LP on-delay (b), period (c), and to calculate LP duty cycle (a/c) and LP on-phase $(\mathrm{b} / \mathrm{c})$. Cycle frequency is increased and LP burst duration is reduced over time in $5 \mu \mathrm{m} D A$. AA specifically prevents the reduction in burst duration, but not the $\sim 20 \%$ increase in cycle frequency. Scale bar, $200 \mathrm{~ms}$. B-D, Scaling LP burst duration with cycle frequency to restore duty cycle requires dynamic SUM0ylation. Changes in mean cycle frequency, burst duration, and duty cycle over the course of $1 \mathrm{~h}$ are plotted; $n>5$ experiments for each indicated experimental treatment. $E$, Dynamic SUMOylation is necessary for $L P$ on-phase recovery. Mean changes in $L P$ on-phase over time are plotted for the three experimental conditions ( $n>5 /$ treatment).

monitored with extracellular recordings from the $l v n$. By $10 \mathrm{~min}$, $5 \mu \mathrm{M}$ DA increased cycle frequency, LP burst duration, and LP duty cycle (Fig. 10A,B). Mean cycle frequency remained elevated throughout the experiment, but burst duration was slowly scaled to exactly compensate for the increase in cycle frequency so that by 50 min duty cycle was restored. Anacardic acid abolished duty cycle recovery (Fig. 10C). In DA + anacardic acid, cycle frequency increased to the same extent as occurred in DA alone. Burst duration also increased, but it remained elevated. There was no scaling of burst duration with cycle frequency, and duty 
cycle did not recover. By 10 min in DA + anacardic acid, the increase in burst duration and duty cycle were noticeably higher than in DA alone, suggesting that the compensatory mechanism may have been initiated before this time point. Anacardic acid alone produced only small changes in circuit output that could not explain the effects of anacardic acid in $5 \mu \mathrm{M} \mathrm{DA}$ (Fig. 10D).

LP phase is also invariant (Hooper, 1997; Bucher et al., 2005; Goaillard et al., 2009; Hooper et al., 2009). Phase characterizes the timing of the burst within the cycle. LP on-phase, which is the point where the first LP spike occurs in a given cycle period, was measured from the $l v n$ (Fig. 10A); $5 \mu \mathrm{M}$ DA initially produced an LP phase advance and caused the first spike to occur earlier in the cycle period, but phase recovered over the course of $1 \mathrm{~h}$ (Fig. $10 E)$. Anacardic acid blocked this recovery in $5 \mu \mathrm{M} \mathrm{DA}$. Anacardic acid alone produced a small, steadily increasing phase advance that could not account for a total lack of phase recovery. In the absence of a change in activity, anacardic acid increased $\mathrm{I}_{\mathrm{A}}$ and decreased $\mathrm{I}_{\mathrm{h}}$ (Fig. $5 C$ ), which should produce a phase delay. This was most likely not observed because anacardic acid blocked SUMO conjugation to all cellular proteins in all network neurons, making its actions on circuit output unpredictable.

\section{Discussion}

Homeostatic processes stabilize neuronal output by producing compensatory changes in synaptic strengths and ionic current densities in response to altered activity (O'Leary and Wyllie, 2011; Davis, 2013). Most models of activity homeostasis concentrate on slow feedback mechanisms, such as activity-dependent regulation of ion channel transcription (Thoby-Brisson and Simmers, 1998; Mizrahi et al., 2001; Khorkova and Golowasch, 2007; Krenz et al., 2014; O'Leary et al., 2014), but rapid compensatory processes are also necessary for stabilization over briefer time scales (Zenke et al., 2017). The major findings of this study were that rapid, activity-dependent regulation of SUMOylation states continuously adjusted ionic current densities over minutes, and disrupting dynamic SUMOylation prevented short-term activity homeostasis; moreover, tonic $5 \mathrm{~nm}$ DA gated this regulation and could permit or prevent ionic current activity dependence. The gating function may ensure that the appropriate mechanisms are enabled to correctly compensate for modifications driven by higher (micromolar) concentrations of DA.

\section{Activity-dependent SUMOylation underpins duty cycle- dependent regulation of LP ionic currents that supports short-term activity homeostasis}

The LP neuron in the crustacean pyloric network is rhythmically active and continuously fires a burst of spikes at a frequency of $\sim 0.5-2 \mathrm{~Hz}$. Two characteristics of LP activity are invariant: duty cycle (burst duration/cycle period), which characterizes the fraction of the period in which LP is active; and phase (LP ondelay/cycle period), which characterizes when in the cycle LP is active. Several other aspects of neuronal activity can vary, including cycle period. This suggests that feedback mechanisms exist to maintain and/or restore duty cycle and phase by scaling burst duration and LP on-delay as cycle period varies. Relatively fast synaptic and intrinsic mechanisms act to maintain phase (Hooper, 1997; Nadim et al., 2003; Rabbah and Nadim, 2005; Mouser et al., 2008; Hooper et al., 2009). Here we investigated a novel feedback mechanism that operated with a time constant of $\sim 10$ min to restore duty cycle and phase.

We discovered that duty cycle can continuously fine-tune LP $\mathrm{I}_{\mathrm{A}}$ and $\mathrm{I}_{\mathrm{h}}$. Increases in duty cycle reduced both currents; decreases in duty cycle enhanced both currents. Duty cycle regulated dy- namic post-translational SUMOylation, which in turn controlled LP $\mathrm{I}_{\mathrm{A}}$ and $\mathrm{I}_{\mathrm{h}}$ densities. Tonic $5 \mathrm{~nm}$ DA gated duty cycle-dependent SUMOylation; it permitted the SUMO conjugation and deconthe SUMO conjugation and deconjugation necessary for LP $\mathrm{I}_{\mathrm{A}}$ activity dependence.

DA-gated SUMOylation was necessary to restore LP duty cycle and phase when they were disrupted during a $1 \mathrm{~h}$ bath application of $5 \mu \mathrm{M}$ DA. Bath-applied DA $(>5 \mu \mathrm{M})$ modulates the intrinsic and synaptic properties of all pyloric neurons to alter circuit output (Flamm and Harris-Warrick, 1986; HarrisWarrick et al., 1995; Rodgers et al., 2011). Here we showed that, by $10 \mathrm{~min}, 5 \mu \mathrm{M}$ DA increased cycle frequency, LP burst duration, and LP duty cycle. Cycle frequency remained elevated throughout the $1 \mathrm{~h}$ application, but LP burst duration was slowly scaled to compensate for the $\sim 20 \%$ increase in cycle frequency so that LP duty cycle was restored by $50 \mathrm{~min}$. Similar to what we previously showed (Rodgers et al., 2011; Krenz et al., 2013), 5 MM DA also produced an LP phase advance by $10 \mathrm{~min}$ that slowly recovered over the hour. Blocking dynamic SUMOylation with anacardic acid prevented the scaling of burst duration and on-delay with cycle frequency and thereby abolished activity homeostasis; neither phase nor duty cycle recovered in $5 \mu \mathrm{M} \mathrm{DA}+10 \mu \mathrm{M}$ anacardic acid. We previously used dynamic clamp to remove duty cycle-dependent regulation of LP $\mathrm{I}_{\mathrm{h}}$ in $5 \mu \mathrm{M}$ DA and found that this also prevented phase recovery (Krenz et al., 2013). The most parsimonious interpretation of these data is that DA-gated, SUMOylation-mediated, duty cycle-dependent regulation of LP ionic conductances contributes to a feedback mechanism that supports activity homeostasis.

How might DA-gated, duty cycle-dependent regulation of LP $\mathrm{I}_{\mathrm{A}}$ and $\mathrm{I}_{\mathrm{h}}$ restore LP on-phase? LP on-phase depends, in part, upon the balance between $\mathrm{I}_{\mathrm{A}}$ and $\mathrm{I}_{\mathrm{h}}$ (Harris-Warrick et al., 1995; Zhao and Golowasch, 2012). LP $\mathrm{I}_{\mathrm{A}}$ and $\mathrm{I}_{\mathrm{h}}$ peak current amplitudes vary across individuals, but the LP $\mathrm{I}_{\mathrm{A}}: \mathrm{I}_{\mathrm{h}}$ ratio does not (Temporal et al., 2012), suggesting that the ratio is actively maintained. Bath application of $5 \mu \mathrm{M}$ DA distorts the ratio. By $10 \mathrm{~min}$ in $5 \mu \mathrm{M} \mathrm{DA}, \mathrm{LP}_{\mathrm{A}}$ was reduced by $\sim 20 \%$, but $\mathrm{I}_{\mathrm{h}}$ was decreased by $<5 \%$ (Zhang et al., 2010; Krenz et al., 2013). This will produce an LP phase advance (Harris-Warrick et al., 1995). However, the accompanying increase in duty cycle will produce an activitydependent decrease in LP $\mathrm{I}_{\mathrm{h}}$ over time, which will restore the $\mathrm{I}_{\mathrm{A}}: \mathrm{I}_{\mathrm{h}}$ ratio and LP on-phase (Krenz et al., 2013). If LP $\mathrm{I}_{\mathrm{A}}$ activity dependence was not turned off by DA, then the initial increase in duty cycle would also produce a further reduction in $\mathrm{LP}_{\mathrm{A}}$. This could potentially create a positive feedback loop if the decrease in LP I $I_{A}$ also contributes to the increase in duty cycle. In sum, the modulatory effects of $5 \mu \mathrm{M} \mathrm{DA}$ and the metamodulatory (gating) effects of $5 \mathrm{~nm}$ DA appear to be complimentary and tailored to simultaneously alter and stabilize distinct activity features.

Ionic current correlations underlie several activity features, and $\mathrm{I}_{\mathrm{h}}$ is dominant in many of these relationships (Zhao and Golowasch, 2012). It is important to identify the correlation specifying burst duration and the activity dependence of the conductances involved to gain insight into how duty cycle and phase restoration are coordinated.

DA permits duty cycle to regulate $L P I_{h}$ through the fast mechanism described here and through a slow mechanism that relies on microRNA, polymerase II transcription and translation (Krenz et al., 2014, 2015). Interestingly, both mechanisms similarly tune LP $\mathrm{I}_{\mathrm{h}}$, suggesting that slow compensatory processes may serve to consolidate the effects of post-translational modifications. Important future directions will be to investigate 
whether other modulators also gate activity dependence, and whether fast and slow mechanisms of modulator-gated activity homeostasis diverge at the level of SUMOylation targets.

\section{The mechanism mediating activity dependence}

The protein(s) whose SUMOylation status was reconfigured in response to a change in duty cycle was not unambiguously identified in these experiments. The most parsimonious interpretation of the existing data is that duty cycle fine-tunes $\mathrm{LP}_{\mathrm{h}}$ and $\mathrm{I}_{\mathrm{A}}$ by altering the SUMOylation status of $\mathrm{HCN}$ and $\mathrm{Kv} 4$ channels. Ion channels can be SUMOylated to influence both their surface expression and biophysical properties (Parker et al., 2016; Plant et al., 2016; Benson et al., 2017). We demonstrated that HCN and Kv4 channels were SUMOylated in lobster nervous system lysates. Increased ion channel SUMOylation in HEK cells overexpressing $\mathrm{HCN}$ or Kv4 enhanced $\mathrm{I}_{\mathrm{h}}$ (Parker et al., 2016) and diminished $\mathrm{I}_{\mathrm{A}}$ (Welch et al., 2018), respectively. Similarly, increasing SUMOylation in LP enhanced $\mathrm{I}_{\mathrm{h}}$ and diminished $\mathrm{I}_{\mathrm{A}}$. Reducing SUMOylation had the opposite effects. For ease of discussion, we will assume that $\mathrm{HCN}$ and $\mathrm{Kv} 4$ channels are the targets of activity-dependent SUMOylation, but we cannot rule out that duty cycle regulates the SUMOylation of another target protein(s) in addition to, or instead of, ion channel $\alpha$-subunits.

The SUMOylation of multiple proteins involved in a given process is often coregulated (Jentsch, and Psakhye, 2013). Duty cycle could regulate the SUMOylation of additional ion channels to achieve LP activity homeostasis. In the simplest case, a single site on each channel would be SUMOylated in an activitydependent fashion, but prediction software indicates that $\mathrm{HCN}$ and $\mathrm{Kv} 4$ channels have the potential to be SUMOylated at multiple sites. Each site could regulate a different aspect of channel function by controlling $\alpha$-subunit interactions with distinct auxiliary proteins that influence channel surface expression and biophysical properties. We did not discern whether SUMOylation regulated LP HCN and Kv4 channel surface expression and/or biophysical properties in this study.

Activity-dependent changes in SUMOylation profiles can be mediated by altering the activity of the SUMOylation machinery and/or its location and/or abundance (Feligioni et al., 2009; Craig et al., 2012; Hickey et al., 2012; Jaafari et al., 2013; Loriol et al., 2013, 2014; Watts, 2013; Nayak and Müller, 2014; Mendes et al., 2016). The targets of the $\mathrm{Ca}^{2+}$-dependent enzymes involved in LP duty cycle-dependent SUMOylation are unknown, but it is possible that these enzymes act on the LP SUMOylation machinery.

\section{The gating mechanism}

Bidirectional, activity-dependent regulation of ion currents relies on two simultaneous processes (Dittmer et al., 2014; Krenz et al., 2015). One process increases the conductance; the other decreases it; and only one of the processes is activity-dependent. DA acts at LP Type 1 DA receptors to gate both processes through PKA (Clark and Baro, 2006; Clark et al., 2008; Zhang et al., 2010; Krenz et al., 2015).

DA most likely gates the activity-independent process by regulating the phosphorylation status of $\mathrm{HCN}$ and $\mathrm{Kv} 4$ channels. The potential for a target protein to be SUMOylated is often determined by its phosphorylation state (Flotho and Melchior, 2013). Different phosphorylation sites on the same protein can permit or prevent SUMOylation (Dustrude et al., 2013, 2016). Thus, by altering the phosphorylation state of $\mathrm{HCN}$ and $\mathrm{Kv} 4$ channels, DA could permit or prevent their SUMOylation, respectively.
DA appears to gate the second process by altering the targets of $\mathrm{Ca}^{2+}$-dependent enzymes (Krenz et al., 2015). The enzyme involved in $\mathrm{I}_{\mathrm{A}}$ activity dependence is not yet known, but we have shown that calcineurin mediates $I_{h}$ activity dependence. Calcineurin decreases LP $\mathrm{I}_{\mathrm{h}}$ in a duty cycle-dependent fashion, but only in the presence of tonic nanomolar DA (Krenz et al., 2015). Here we showed that a decrease in LP $\mathrm{I}_{\mathrm{h}}$ was associated with SUMO deconjugation. Thus, we hypothesize that calcineurin orchestrates SUMO deconjugation from HCN channels. It is not clear whether calcineurin acts on the SUMOylation machinery and/or the HCN channel. Calcineurin, PKA, and Kv4 can be colocalized in multiprotein complexes by A-kinase-anchoring proteins (Lin et al., 2011; Woolfrey and Dell'Acqua, 2015). Potentially, DA could cause the release of calcineurin from an A-kinase anchoring protein complex, simultaneously making it unavailable to Kv4 but available to $\mathrm{HCN}$ channels.

\section{References}

Baro DJ, Levini RM, Kim MT, Willms AR, Lanning CC, Rodriguez HE, Harris-Warrick RM (1997) Quantitative single-cell-reverse transcriptionPCR demonstrates that A-current magnitude varies as a linear function of shal gene expression in identified stomatogastric neurons. J Neurosci 17: 6597-6610. CrossRef Medline

Baro DJ, Ayali A, French L, Scholz NL, Labenia J, Lanning CC, Graubard K, Harris-Warrick RM (2000) Molecular underpinnings of motor pattern generation: differential targeting of shal and shaker in the pyloric motor system. J Neurosci 20:6619-6630. CrossRef Medline

Baro DJ, Quiñones L, Lanning CC, Harris-Warrick RM, Ruiz M (2001) Alternate splicing of the shal gene and the origin of $\mathrm{I}(\mathrm{A})$ diversity among neurons in a dynamic motor network. Neuroscience 106:419-432. CrossRef Medline

Benson M, Iñiguez-Lluhi JA, Martens J (2017) SUMO modification of ion channels. Adv Exp Med Biol 963:127-141. CrossRef Medline

Bucher D, Prinz AA, Marder E (2005) Animal-to-animal variability in motor pattern production in adults and during growth. J Neurosci 25:16111619. CrossRef Medline

Chamberlain SE, Gonzalez-González IM, Wilkinson KA, Konopacki FA, Kantamneni S, Henley JM, Mellor JR (2012) SUMOylation and phosphorylation of GluK2 regulate kainate receptor trafficking and synaptic plasticity. Nat Neurosci 15:845-852. CrossRef Medline

Clark MC, Baro DJ (2006) Molecular cloning and characterization of crustacean type-one dopamine receptors: DlalphaPan and D1betaPan. Comp Biochem Physiol B Biochem Mol Biol 143:294-301. CrossRef Medline

Clark MC, Dever TE, Dever JJ, Xu P, Rehder V, Sosa MA, Baro DJ (2004) Arthropod 5-HT2 receptors: a neurohormonal receptor in decapod crustaceans that displays agonist independent activity resulting from an evolutionary alteration to the DRY motif. J Neurosci 24:3421-3435. CrossRef Medline

Clark MC, Khan R, Baro DJ (2008) Crustacean dopamine receptors: localization and $\mathrm{G}$ protein coupling in the stomatogastric ganglion. J Neurochem 104:1006-1019. CrossRef Medline

Craig TJ, Jaafari N, Petrovic MM, Jacobs SC, Rubin PP, Mellor JR, Henley JM (2012) Homeostatic synaptic scaling is regulated by protein SUMOylation. J Biol Chem 287:22781-22788. CrossRef Medline

Cujec TP, Okamoto H, Fujinaga K, Meyer J, Chamberlin H, Morgan DO, Peterlin BM (1997) The HIV transactivator TAT binds to the CDKactivating kinase and activates the phosphorylation of the carboxyterminal domain of RNA polymerase II. Genes Dev 11:2645-2657. CrossRef Medline

Davis GW (2013) Homeostatic signaling and the stabilization of neural function. Neuron 80:718-728. CrossRef Medline

Dittmer PJ, Dell'Acqua ML, Sather WA (2014) $\mathrm{Ca}^{2+} /$ calcineurindependent inactivation of neuronal L-type $\mathrm{Ca}^{2+}$ channels requires priming by AKAP-anchored protein kinase A. Cell Rep 7:1410-1416. CrossRef Medline

Driscoll HE, Muraro NI, He M, Baines RA (2013) Pumilio-2 regulates translation of Nav1.6 to mediate homeostasis of membrane excitability. J Neurosci 33:9644-9654. CrossRef Medline

Dupuis JP, Ladépêche L, Seth H, Bard L, Varela J, Mikasova L, Bouchet D, Rogemond V, Honnorat J, Hanse E, Groc L (2014) Surface dynamics of 
GluN2B-NMDA receptors controls plasticity of maturing glutamate synapses. EMBO J 33:842-861. CrossRef Medline

Dustrude ET, Moutal A, Yang X, Wang Y, Khanna M, Khanna R (2016) Hierarchical CRMP2 posttranslational modifications control NaV1.7 function. Proc Natl Acad Sci U S A 113:E8443-E8452. CrossRef

Dustrude ET, Wilson SM, Ju W, Xiao Y, Khanna R (2013) CRMP2 protein SUMOylation modulates NaV1.7 channel trafficking. J Biol Chem 288: 24316-24331. CrossRef

Fawell S, Seery J, Daikh Y, Moore C, Chen LL, Pepinsky B, Barsoum J (1994) Tat-mediated delivery of heterologous proteins into cells. Proc Natl Acad Sci U S A 91:664-668. CrossRef Medline

Feligioni M, Nishimune A, Henley JM (2009) Protein SUMOylation modulates calcium influx and glutamate release from presynaptic terminals. Eur J Neurosci 29:1348-1356. CrossRef Medline

Flamm RE, Harris-Warrick RM (1986) Aminergic modulation in lobster stomatogastric ganglion: I. Effects on motor pattern and activity of neurons within the pyloric circuit. J Neurophysiol 55:847-865. CrossRef Medline

Flotho A, Melchior F (2013) Sumoylation: a regulatory protein modification in health and disease. Annu Rev Biochem 82:357-385. CrossRef Medline

Fukuda I, Ito A, Hirai G, Nishimura S, Kawasaki H, Saitoh H, Kimura K, Sodeoka M, Yoshida M (2009) Ginkgolic acid inhibits protein SUMOylation by blocking formation of the E1-SUMO intermediate. Chem Biol 16:133-140. CrossRef Medline

Goaillard JM, Taylor AL, Schulz DJ, Marder E (2009) Functional consequences of animal-to-animal variation in circuit parameters. Nat Neurosci 12:1424-1430. CrossRef Medline

Golowasch J, Abbott LF, Marder E (1999a) Activity-dependent regulation of potassium currents in an identified neuron of the stomatogastric ganglion of the crab Cancer borealis. J Neurosci 19:RC33. CrossRef Medline

Golowasch J, Casey M, Abbott LF, Marder E (1999b) Network stability from activity-dependent regulation of neuronal conductances. Neural Comput 11:1079-1096. CrossRef Medline

Harris-Warrick RM (2011) Neuromodulation and flexibility in central pattern generator networks. Curr Opin Neurobiol 21:685-692. CrossRef Medline

Harris-Warrick RM, Coniglio LM, Levini RM, Gueron S, Guckenheimer J (1995) Dopamine modulation of two subthreshold currents produces phase shifts in activity of an identified motoneuron. J Neurophysiol 74: 1404-1420. CrossRef Medline

Harris-Warrick RM, Johnson BR, Peck JH, Kloppenburg P, Ayali A, Skarbinski J (1998) Distributed effects of dopamine modulation in the crustacean pyloric network. Ann N Y Acad Sci 860:155-167. CrossRef Medline

Henley JM, Craig TJ, Wilkinson KA (2014) Neuronal SUMOylation: mechanisms, physiology, and roles in neuronal dysfunction. Physiol Rev 94: 1249-1285. CrossRef Medline

Heubl M, Zhang J, Pressey JC, Al Awabdh S, Renner M, Gomez-Castro F, Moutkine I, Eugène E, Russeau M, Kahle KT, Poncer JC, Lévi S (2017) GABAA receptor dependent synaptic inhibition rapidly tunes KCC2 activity via the $\mathrm{Cl}(-)$-sensitive WNK1 kinase. Nat Commun 8:1776. CrossRef Medline

Hickey CM, Wilson NR, Hochstrasser M (2012) Function and regulation of SUMO proteases. Nat Rev Mol Cell Biol 13:755-766. CrossRef Medline

Hooper SL (1997) Phase maintenance in the pyloric pattern of the lobster (Panulirus interruptus) stomatogastric ganglion. J Comput Neurosci 4:191-205. CrossRef Medline

Hooper SL, Buchman E, Weaver AL, Thuma JB, Hobbs KH (2009) Slow conductances could underlie intrinsic phase-maintaining properties of isolated lobster (Panulirus interruptus) pyloric neurons. J Neurosci 29: 1834-1845. CrossRef Medline

Jaafari N, Konopacki FA, Owen TF, Kantamneni S, Rubin P, Craig TJ, Wilkinson KA, Henley JM (2013) SUMOylation is required for glycineinduced increases in AMPA receptor surface expression (ChemLTP) in hippocampal neurons. PLoS One 8:e52345. CrossRef Medline

Jentsch S, Psakhye I (2013) Control of nuclear activities by substrate-selective and protein-group SUMOylation. Annu Rev Genet 47:167-186. CrossRef

Johnson BR, Kloppenburg P, Harris-Warrick RM (2003) Dopamine modulation of calcium currents in pyloric neurons of the lobster stomatogastric ganglion. J Neurophysiol 90:631-643. CrossRef Medline

Khorkova O, Golowasch J (2007) Neuromodulators, not activity, control coordinated expression of ionic currents. J Neurosci 27:8709-8718. CrossRef Medline

Kiehn O, Harris-Warrick RM (1992) 5-HT modulation of hyperpolarizationactivated inward current and calcium-dependent outward current in a crustacean motor neuron. J Neurophysiol 68:496-508. CrossRef Medline

Kirchheim F, Tinnes S, Haas CA, Stegen M, Wolfart J (2013) Regulation of action potential delays via voltage-gated potassium Kv1.1 channels in dentate granule cells during hippocampal epilepsy. Front Cell Neurosci 7:248. CrossRef Medline

Krenz WD, Hooper RM, Parker AR, Prinz AA, Baro DJ (2013) Activation of high and low affinity dopamine receptors generates a closed loop that maintains a conductance ratio and its activity correlate. Front Neural Circuits 7:169. CrossRef Medline

Krenz WD, Parker AR, Rodgers EW, Baro DJ (2014) Dopaminergic tone persistently regulates voltage-gated ion current densities through the D1R-PKA axis, RNA polymerase II transcription, RNAi, mTORC1, and translation. Front Cell Neurosci 8:39. CrossRef Medline

Krenz WD, Rodgers EW, Baro DJ (2015) Tonic 5nM DA stabilizes neuronal output by enabling bidirectional activity-dependent regulation of the hyperpolarization activated current via PKA and calcineurin. PLoS One. 10:e0117965. CrossRef Medline

LeMasson G, Marder E, Abbott LF (1993) Activity-dependent regulation of conductances in model neurons. Science 259:1915-1917. CrossRef Medline

Lin L, Sun W, Kung F, Dell'Acqua ML, Hoffman DA (2011) AKAP79/150 impacts intrinsic excitability of hippocampal neurons through phosphoregulation of A-type $\mathrm{K}^{+}$channel trafficking. J Neurosci 31:1323-1332. CrossRef Medline

Linsdell P, Moody WJ (1994) $\mathrm{Na}^{+}$channel mis-expression accelerates $\mathrm{K}^{+}$ channel development in embryonic Xenopus laevis skeletal muscle. J Physiol 480:405-410. CrossRef Medline

Loriol C, Khayachi A, Poupon G, Gwizdek C, Martin S (2013) Activitydependent regulation of the sumoylation machinery in rat hippocampal neurons. Biol Cell 105:30-45. CrossRef Medline

Loriol C, Cassé F, Khayachi A, Poupon G, Chafai M, Deval E, Gwizdek C, Martin S (2014) mGlu5 receptors regulate synaptic sumoylation via a transient PKC-dependent diffusional trapping of Ubc9 into spines. Nat Commun 5:5113. CrossRef Medline

Marder E (2011) Variability, compensation, and modulation in neurons and circuits. PNAS 108:15542-15548. CrossRef Medline

Marder E, Bucher D (2007) Understanding circuit dynamics using the stomatogastric nervous system of lobsters and crabs. Annu Rev Physiol 69: 291-316. CrossRef Medline

Mendes AV, Grou CP, Azevedo JE, Pinto MP (2016) Evaluation of the activity and substrate specificity of the human SENP family of SUMO proteases. Biochim Biophys Acta 1863:139-147. CrossRef Medline

Misonou H, Mohapatra DP, Park EW, Leung V, Zhen D, Misonou K, Anderson AE, Trimmer JS (2004) Regulation of ion channel localization and phosphorylation by neuronal activity. Nat Neurosci 7:711-718. CrossRef Medline

Mizrahi A, Dickinson PS, Kloppenburg P, Fénelon V, Baro DJ, HarrisWarrick RM, Meyrand P, Simmers J (2001) Long-term maintenance of channel distribution in a central pattern generator neuron by neuromodulatory inputs revealed by decentralization in organ culture. J Neurosci 21:7331-7339. CrossRef Medline

Mohapatra DP, Misonou H, Pan SJ, Held JE, Surmeier DJ, Trimmer JS (2009) Regulation of intrinsic excitability in hippocampal neurons by activity-dependent modulation of the KV2.1 potassium channel. Channels (Austin) 3:46-56. CrossRef Medline

Mouser C, Nadim F, Bose A (2008) Maintaining phase of the crustacean tri-phasic pyloric rhythm. J Math Biol 57:161-181. CrossRef Medline

Mukhopadhyay D, Dasso M (2007) Modification in reverse: the SUMO proteases. Trends Biochem Sci 32:286-295. CrossRef Medline

Nadim F, Boothe V, Bose A, Manor Y (2003) Short-term synaptic dynamics promote phase maintenance in multi-phasic rhythms. Neurocomputing 52:79-87.

Nayak A, Müller S (2014) SUMO-specific proteases/isopeptidases: SENPs and beyond. Genome Biol 15:422. CrossRef Medline

Oginsky MF, Rodgers EW, Clark MC, Simmons R, Krenz WD, Baro DJ (2010) $\mathrm{D}(2)$ receptors receive paracrine neurotransmission and are consistently targeted to a subset of synaptic structures in an identified neuron 
of the crustacean stomatogastric nervous system. J Comp Neurol 518: 255-276. CrossRef Medline

O'Leary T, Wyllie DJ (2011) Neuronal homeostasis: time for a change? J Physiol 589:4811-4826. CrossRef Medline

O'Leary T, Williams AH, Franci A, Marder E (2014) Cell types, network homeostasis, and pathological compensation from a biologically plausible ion channel expression model. Neuron 82:809-821. CrossRef Medline

Olypher AV, Prinz AA (2010) Geometry and dynamics of activitydependent homeostatic regulation in neurons. J Comput Neurosci 28: 361-374. CrossRef Medline

Ouyang Q, Goeritz M, Harris-Warrick RM (2007) Panulirus interruptus ih-channel gene PIIH: modification of channel properties by alternative splicing and role in rhythmic activity. J Neurophysiol 97:3880-3892. CrossRef Medline

Parker AR, Welch MA, Forster LA, Tasneem SM, Dubhashi JA, Baro DJ (2016) SUMOylation of the hyperpolarization-activated cyclic nucleotide-gated channel 2 increases surface expression and the maximal conductance of the hyperpolarization-activated current. Front Mol Neurosci 9:168. CrossRef Medline

Peng IF, Wu CF (2007) Drosophila cacophony channels: a major mediator of neuronal $\mathrm{Ca}^{2+}$ currents and a trigger for $\mathrm{K}^{+}$channel homeostatic regulation. J Neurosci 27:1072-1081. CrossRef Medline

Plant LD, Marks JD, Goldstein SA (2016) SUMOylation of $\mathrm{Na}_{\mathrm{V}} 1.2$ channels mediates the early response to acute hypoxia in central neurons. eLife 5:e20054. CrossRef Medline

Pozzi D, Lignani G, Ferrea E, Contestabile A, Paonessa F, D'Alessandro R, Lippiello P, Boido D, Fassio A, Meldolesi J, Valtorta F, Benfenati F, Baldelli P (2013) REST/NRSF-mediated intrinsic homeostasis protects neuronal networks from hyperexcitability. EMBO J 32:2994-3007. CrossRef Medline

Prinz AA, Bucher D, Marder E (2004) Similar network activity from disparate circuit parameters. Nat Neurosci 7:1345-1352. CrossRef Medline

Qi Y, Wang J, Bomben VC, Li DP, Chen SR, Sun H, Xi Y, Reed JG, Cheng J, Pan HL, Noebels JL, Yeh ET (2014) Hyper-SUMOylation of the Kv7 potassium channel diminishes the M-current leading to seizures and sudden death. Neuron 83:1159-1171. CrossRef Medline

Rabbah P, Nadim F (2005) Synaptic dynamics do not determine proper phase of activity in a central pattern generator. J Neurosci 25:1126911278. CrossRef Medline

Ransdell JL, Temporal S, West NL, Leyrer ML, Schulz DJ (2013) Characterization of inward currents and channels underlying burst activity in motoneurons of crab cardiac ganglion. J Neurophysiol 110:42-54. CrossRef Medline

Rodgers EW, Fu JJ, Krenz WD, Baro DJ (2011) Tonic nanomolar dopamine enables an activity-dependent phase recovery mechanism that persistently alters the maximal conductance of the hyperpolarization-activated current in a rhythmically active neuron. J Neurosci 31:16387-16397. CrossRef Medline

Rodgers EW, Krenz WD, Jiang X, Li L, Baro DJ (2013) Dopaminergic tone regulates transient potassium current maximal conductance through a translational mechanism requiring D1Rs, cAMP/PKA, Erk and mTOR. BMC Neurosci 14:143. CrossRef Medline

Romer SH, Deardorff AS, Fyffe RE (2016) Activity-dependent redistribu- tion of Kv2.1 ion channels on rat spinal motoneurons. Physiol Rep 4:e13039. CrossRef Medline

Romer SH, Dominguez KM, Gelpi MW, Deardorff AS, Tracy RC, Fyffe RE (2014) Redistribution of Kv2.1 ion channels on spinal motoneurons following peripheral nerve injury. Brain Res 1547:1-15. CrossRef Medline

Schulz DJ, Goaillard JM, Marder E (2006) Variable channel expression in identified single and electrically coupled neurons in different animals. Nat Neurosci 9:356-362. CrossRef Medline

Selverston AI, Russell DF, Miller JP (1976) The stomatogastric nervous system: structure and function of a small neural network. Prog Neurobiol 7:215-290. CrossRef Medline

Sun H, Lu L, Zuo Y, Wang Y, Jiao Y, Zeng WZ, Huang C, Zhu MX, Zamponi GW, Zhou T, Xu TL, Cheng J, Li Y (2014) Kainate receptor activation induces glycine receptor endocytosis through PKC deSUMOylation. Nat Commun 5:4980. CrossRef Medline

Swensen AM, Bean BP (2005) Robustness of burst firing in dissociated Purkinje neurons with acute or long-term reductions in sodium conductance. J Neurosci 25:3509-3520. CrossRef Medline

Temporal S, Desai M, Khorkova O, Varghese G, Dai A, Schulz DJ, Golowasch J (2012) Neuromodulation independently determines correlated channel expression and conductance levels in motor neurons of the stomatogastric ganglion. J Neurophysiol 107:718-727. CrossRef Medline

Temporal S, Lett KM, Schulz DJ (2014) Activity-dependent feedback regulates correlated ion channel mRNA levels in single identified motor neurons. Curr Biol 24:1899-1904. CrossRef Medline

Thoby-Brisson M, Simmers J (1998) Neuromodulatory inputs maintain expression of a lobster motor pattern-generating network in a modulationdependent state: evidence from long-term decentralization in vitro. J Neurosci 18:2212-2225. CrossRef Medline

Tierney AJ, Harris-Warrick RM (1992) Physiological role of the transient potassium current in the pyloric circuit of the lobster stomatogastric ganglion. J Neurophysiol 67:599-609. CrossRef Medline

Watts FZ (2013) Starting and stopping SUMOylation: what regulates the regulator? Chromosoma 122:451-463. CrossRef Medline

Welch MA, Forster LA, Atlas SI, Baro DJ (2018) SUMOylation of the mouse voltage-gated potassium channel Kv4.2 at two distinct sites independently regulates surface expression and the biophysical properties of the A-type potassium current (IA) (Program No. 558.06), Neuroscience Meeting Planner. San Diego: Society for Neuroscience.

Woolfrey KM, Dell'Acqua ML (2015) Coordination of protein phosphorylation and dephosphorylation in synaptic plasticity. J Biol Chem 290: 28604-28612. CrossRef Medline

Xiong D, Li T, Dai H, Arena AF, Plant LD, Goldstein SA (2017) SUMOylation determines the voltage required to activate cardiac IKs channels. Proc Natl Acad Sci U S A 114:E6686-E6694. CrossRef Medline

Zenke F, Gerstner W, Ganguli S (2017) The temporal paradox of Hebbian learning and homeostatic plasticity. Curr Opin Neurobiol 43:166-176. CrossRef Medline

Zhang H, Rodgers EW, Krenz WD, Clark MC, Baro DJ (2010) Cell specific dopamine modulation of the transient potassium current in the pyloric network by the canonical D1 receptor signal transduction cascade. J Neurophysiol 104:873-884. CrossRef Medline

Zhao S, Golowasch J (2012) Ionic current correlations underlie the global tuning of large numbers of neuronal activity attributes. J Neurosci 32 : 13380-13388. CrossRef Medline 